\title{
NUMERICAL INVESTIGATION OF THE SPACE-TRUSS WITH REINFORCE OF THE STAMPED CONNECTION AFTER CALIBRATION MODEL IN EXPERIMENTAL STUDY.
}

\author{
C. A. S. de Freitas ${ }^{1}$, O.R.O. Cavalcante ${ }^{1}$, R. M. Araujo ${ }^{1}$, G. M. Araújo ${ }^{1}$ e E. C. Sousa ${ }^{1}$ \\ ${ }^{1}$ Grupo de Pesquisa em Engenharia Estrutural do Cariri, Universidade Federal do Ceará - \\ Campus Cariri, Av. Tenente Raimundo Rocha S/N, Cidade Universitária, Juazeiro do Norte, \\ Ceará, Brasil andrefreitas@ cariri.ufc.br, http://www.cariri.ufc.br
}

\begin{abstract}
Space trusses consist of bars tubular section linking in the $3 D$ form in the end members. There are several types of connections to attach these members. The most popular is the staking endflattened connection. The reduced cost and the fast assemblage of the truss are among the advantages of the staking end-flattened connection on $3 D$ trusses. However, such connections present disadvantages like eccentricities and stiffness weakening of the tubular members. Several accidents in space structures using this type of connection have also been reported in Brazil. This research presents suggestions to ensure greater safety for truss structures that use the typical node. It is proposed, initially, the use of reinforcement and constructive correction in the connection in order to increase its capacity. The bases for this are the reduction in the eccentricity and the increase in the rigidity of the typical node connection. In this work, based on computer simulations after experimental lab tests, small changes on the staking end-flattened connections such as reinforcement and eccentricity correction are evaluated. The results show an increase of $68 \%$ for local collapse and $17 \%$ for global collapse in the truss load carrying capacity when the suggested changes proposed in this article are used for the staking end-flattened connections.
\end{abstract}

Keywords: Truss load capacity, space trusses, end-flattened connection.

\section{INTRODUÇÃO}

A Figura 1 apresenta os elementos que compõem uma estrutura treliçada tridimensional com nó típico. O nó da estrutura ou ligação é o ponto de intercessão das barras (banzos e diagonais). Nos modelos de cálculo normalmente as ligações são consideradas como nós rotulados com cargas axiais centradas.

Existem diversos tipos de ligação, no entanto, a mais aplicada no Brasil são as ligações com nó típico (Figura 1). Tal fato é justificado pelo baixo custo e simplicidade de execução. Porém este é o que apresenta o maior número de problemas estruturais. Este nó apresenta excentricidade dos esforços, formação de charneira plástica, excesso de rotação e colapso dos elementos com carga inferior as previstas [6]. 


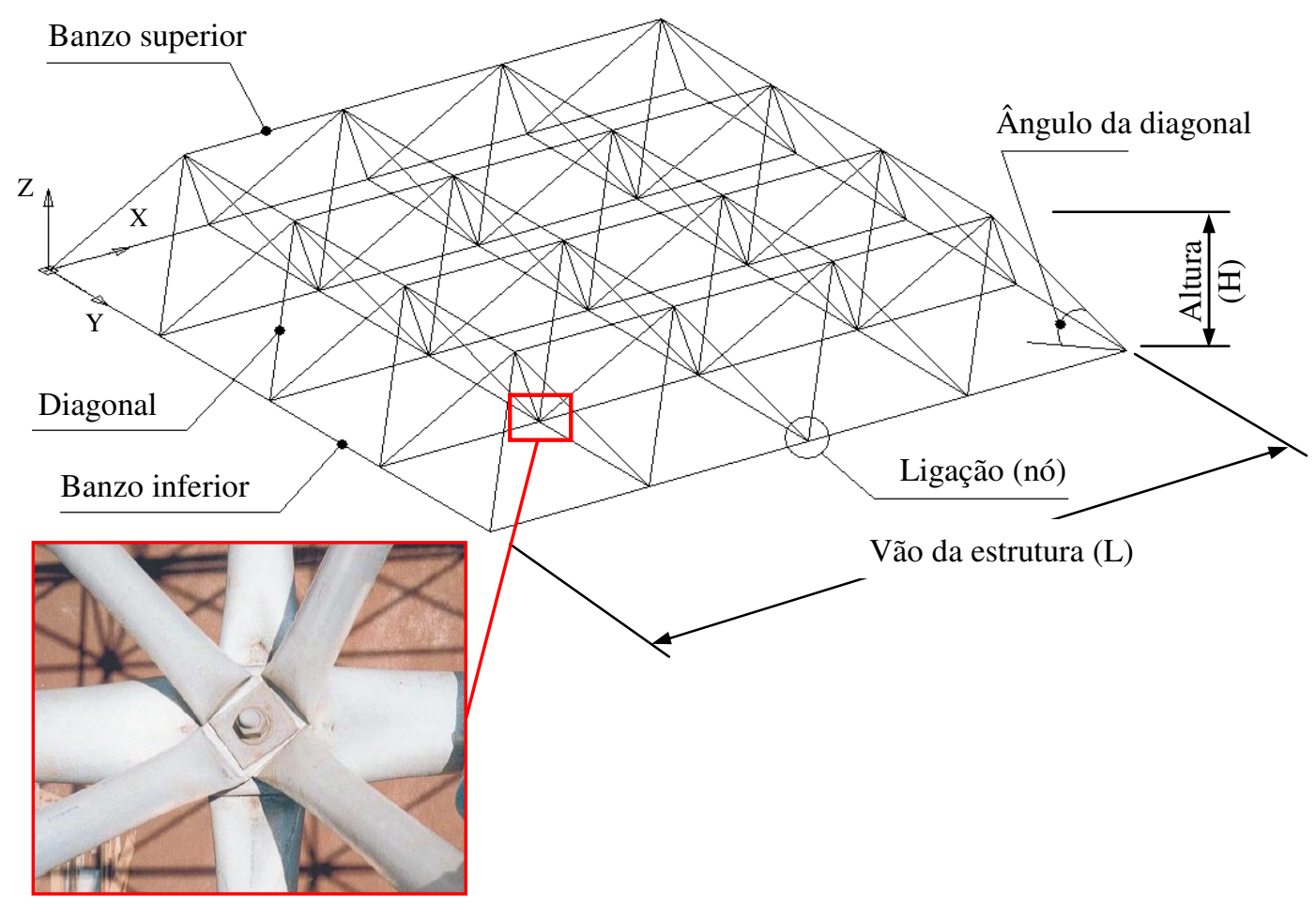

Figura 1. Elementos de uma estrutura espacial com nó típico [5].

Acidentes já foram registrados devido ao colapso do nó. Foi o caso do centro de convenções de Manaus, onde ocorreu em 1994 um colapso global da estrutura da coberta (Figura 2).

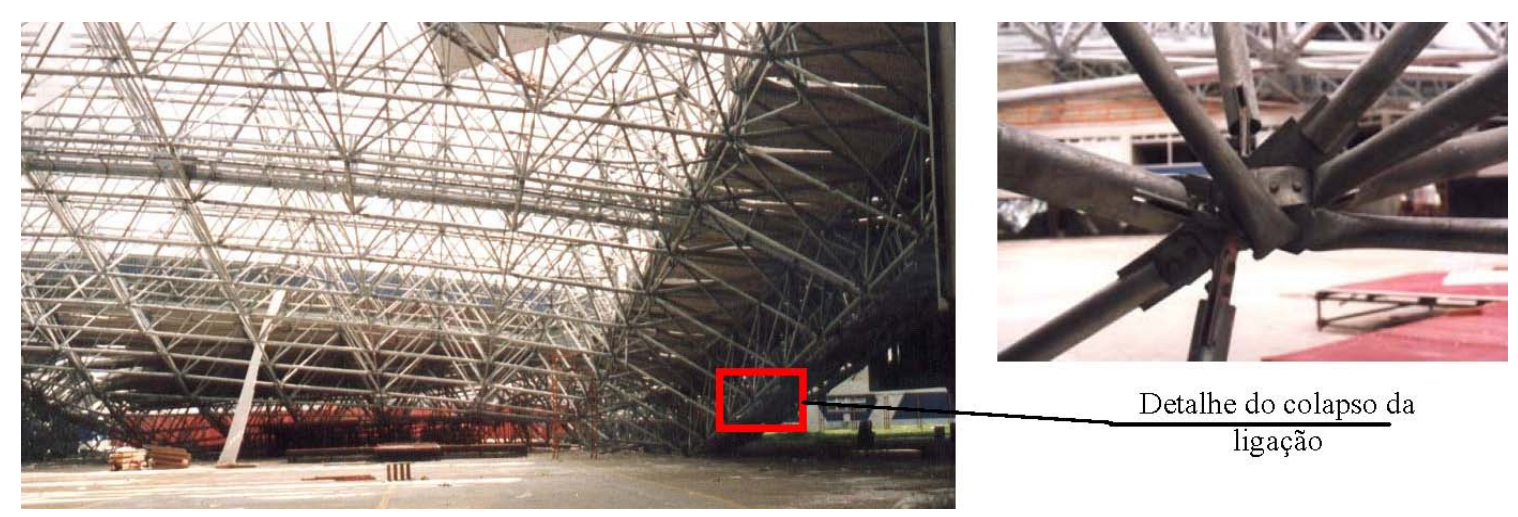

Figura 2. Acidente no centro de convenções de Manaus [6].

\section{PROPOSTA DO ESTUDO}

A proposta da pesquisa é uma correção na excentricidade da ligação típica (Figura 3), utilizando um distanciador (Figura 4). Neste caso note a correção da excentricidade "E2", aplicando uma distância "d" igual a "E2" entre os banzos e diagonais. Desta forma os pontos A e B podem ser considerados como sobrepostos. 


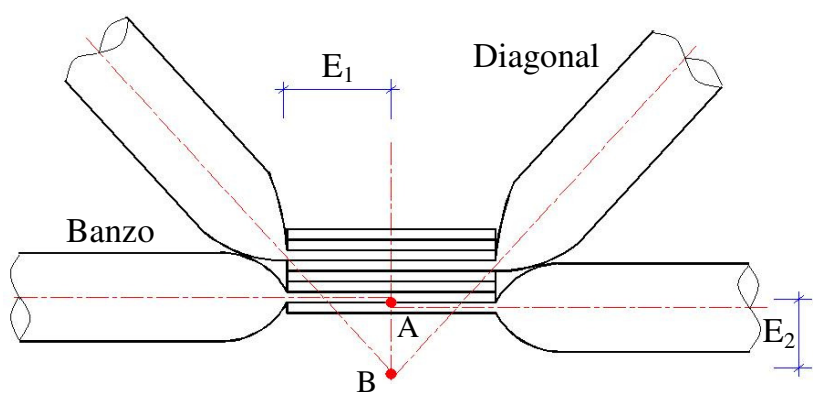

Figura 3. Excentricidade no nó típico.

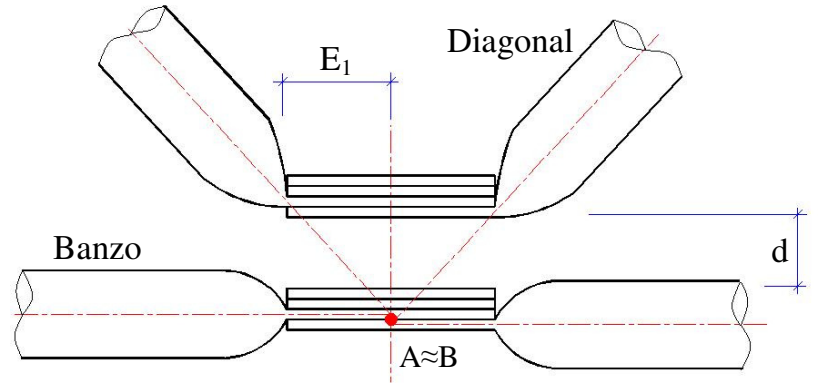

Figura 4. Correção da excentricidade.

Este trabalho propõe uma distância "d", para o distanciador, de acordo com a Equação (1). Sendo: "H" a altura da estrutura, " $\ell$ " o comprimento de um módulo da estrutura, " $E_{1}$ " a metade do comprimento amassado do tubo, "t" a espessura do tubo. Esta formulação é validade para estruturas espaciais com configuração quadrado sobre quadrado, com diâmetro dos elementos do banzo igual ao diâmetro das diagonais. A formulação geral para os demais casos pode ser apreciada na tese de doutorado de Freitas [4].

$$
d=\frac{2 H E_{1}}{\ell \sqrt{2}-4 E_{1}}-8 t
$$

\section{ETAPAS ANTERIORES A ESTE TRABALHO}

\subsection{Estudo numérico preliminar}

A Figura 5 apresenta o modelo do protótipo da treliça tridimensional padrão que foi adotada. Note um sistema modular com pirâmides com base de $1000 \mathrm{~mm}$ e altura de $707 \mathrm{~mm}$. $\mathrm{O}$ ângulo de inclinação das diagonais adotado como sendo de $45^{\circ}$. Os banzos e diagonais são compostos com tubos de diâmetro de $25,4 \mathrm{~mm}$ e parede de $1,5 \mathrm{~mm}$.

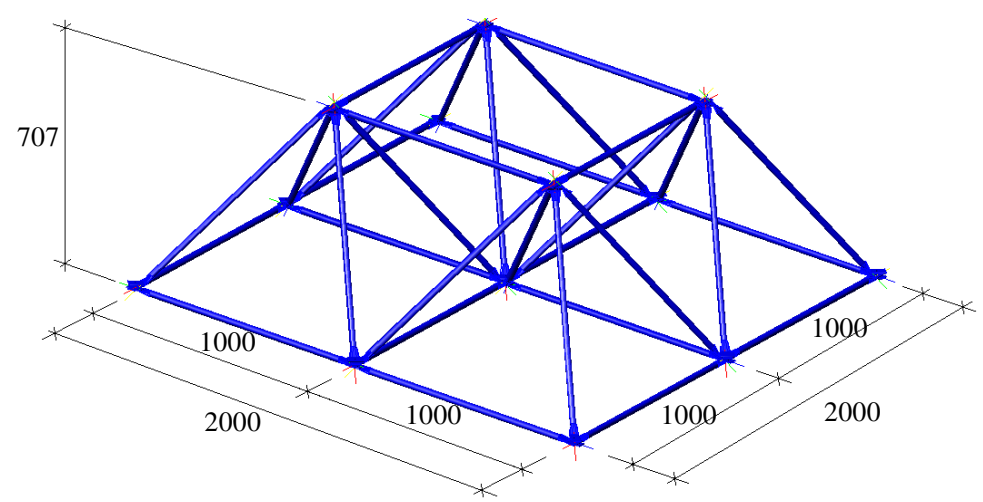

Figura 5. Modelo da estrutura treliçada tridimensional, cotas em milímetro.

Os resultados numéricos dos deslocamentos verticais nodais dos modelos podem ser apreciados nos diagramas das Figuras 6, 7 e 8, respectivamente, modelo com ligação ideal (LI - Fig.15), ligação típica (LT - Fig.16) e ligação típica com distanciador (LTD - Fig.17). A 
escala da deformada é 15 vezes. A Figura 9 mostra um comparativo entre os deslocamentos dos modelos. É possível notar a melhoria da ligação LTD em relação à ligação LT.

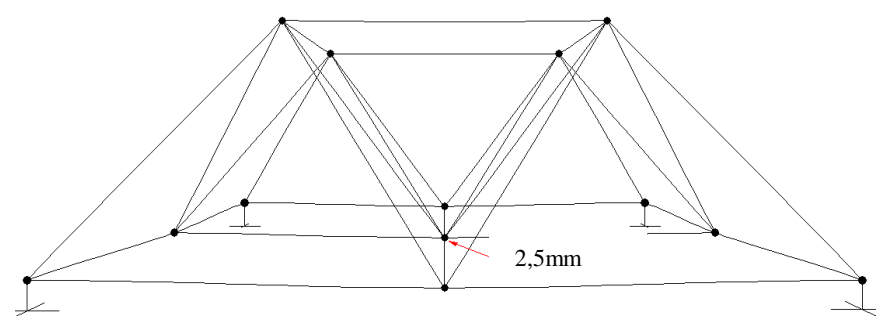

Figura 6. Deslocamento vertical - LI.

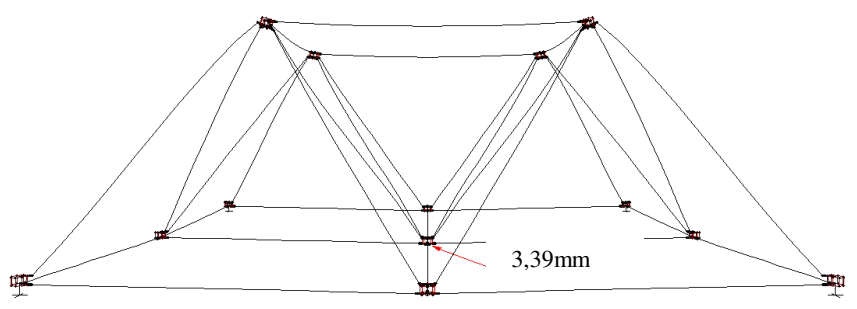

Figura 8. Deslocamento vertical - LTD.

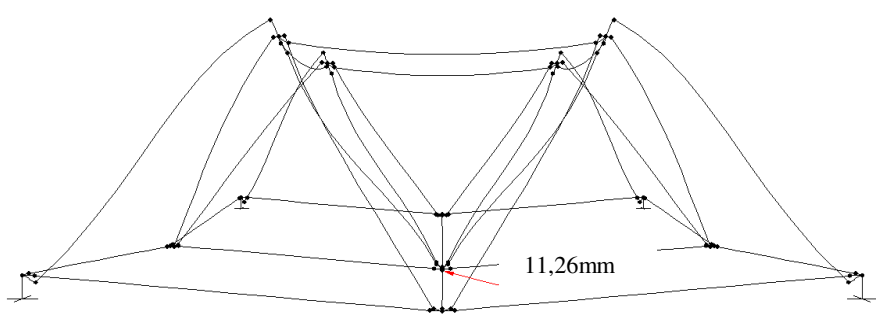

Figura 7. Deslocamento vertical - LT.

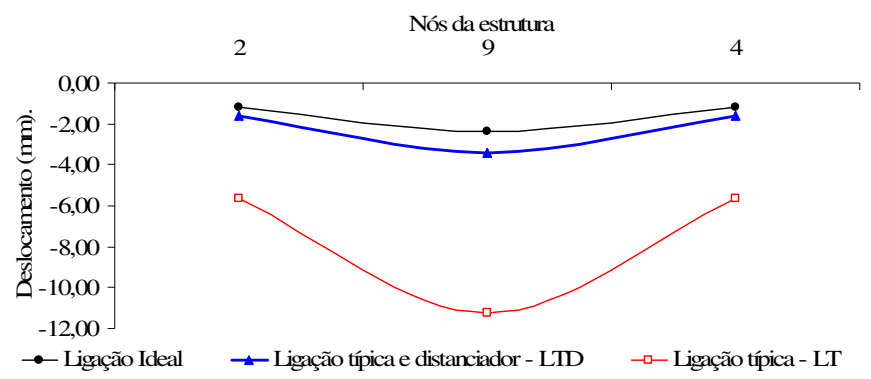

Figura 9. Comparação dos deslocamentos.

\subsection{Estudo experimental em modelo reduzido}

Foram realizados três ensaios com cada modelo (Fig.13a e 13b), totalizando seis ensaios estáticos. A Figura 10 mostra uma visão geral do acompanhamento dos ensaios. O colapso local da ligação com nós típicos (LTE) foi com uma carga "P" de 25,0kN no nó 9 (central), caracterizado por um excesso de deformação no nó, Figura 11. O colapso das estruturas com nó típico reforçado (LTDCE) foi evidenciado a uma carga "P" de 42,0kN no nó 9 (central). Tal colapso foi caracterizado pela flambagem abrupta de um elemento comprimido, Figura 12.

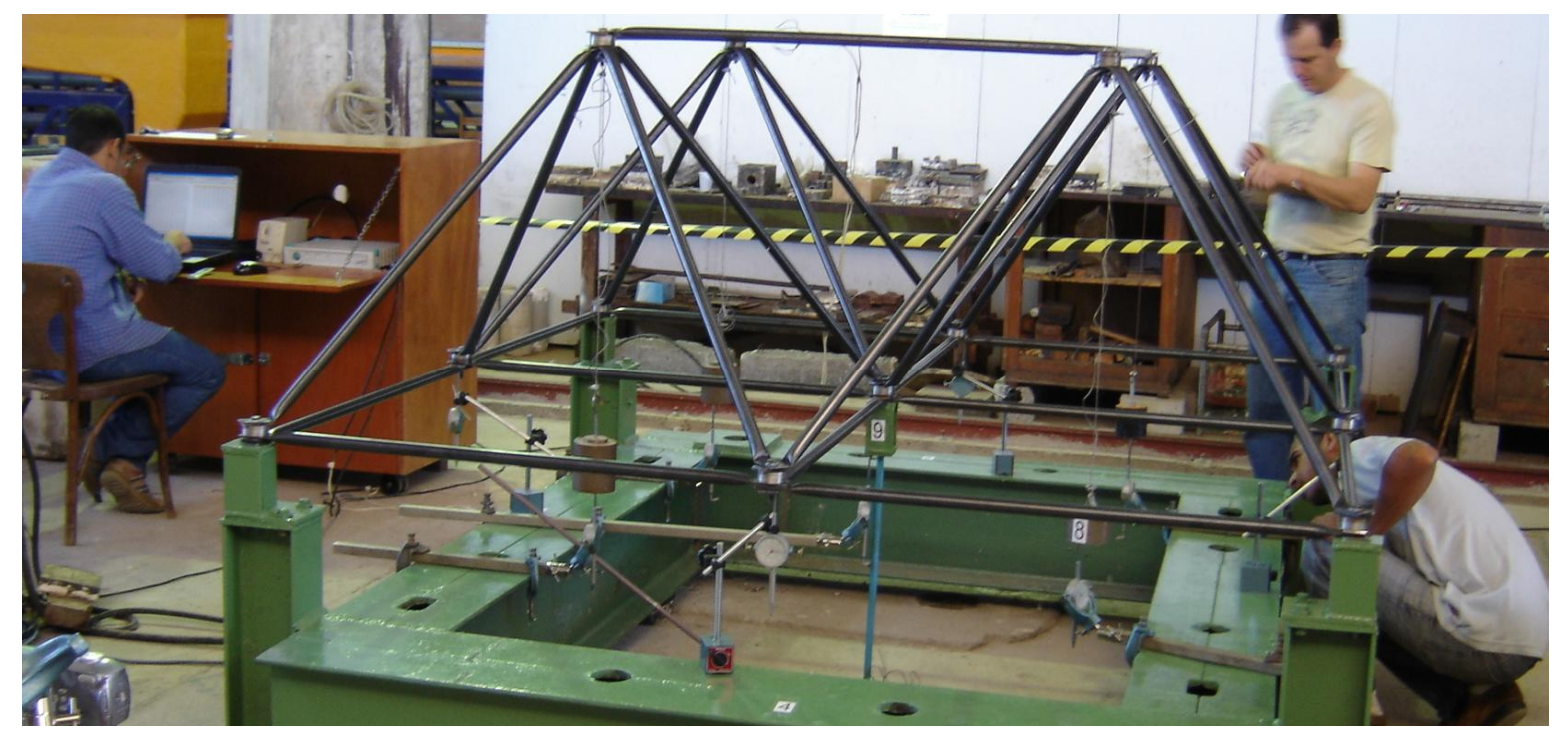

Figura 10. Esquema geral do acompanhamento dos ensaios. 


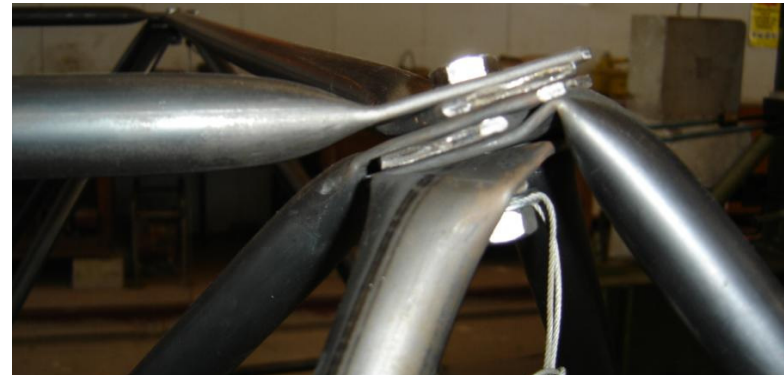

Figura 11. Charneira plástica - LTE $(25 \mathrm{kN})$.

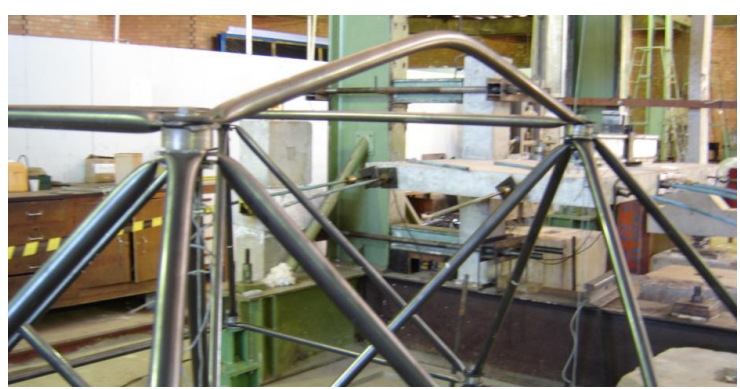

Figura 12. Compressão - LTDCE (42kN).

O gráfico da Figura 14 apresenta os valores de carga de colapso para a estrutura estudada nos ensaios experimentais e normas. Quanto à aplicação das normas "AISC-LRFD" $(40,41 \mathrm{kN})$ [1], "NBR8800" (39,2kN) [2] e "EUROCODE" (36,54kN) [3], observou-se que são superiores $61,64 \%, 56,8 \%$ e $46,16 \%$, respectivamente, ao valor do colapso da estrutura "LT" $(25 \mathrm{kN})$. Quanto à carga de colapso da estrutura com nó típico, distanciador "LTDC" $(42 \mathrm{kN})$, foi observado um acréscimo de $68 \%$ em relação à carga do nó "LT" $(25 \mathrm{kN})$.

(a) LT

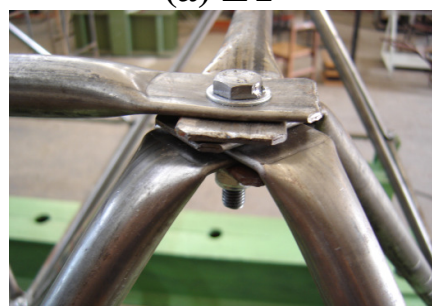

(b) LTDC

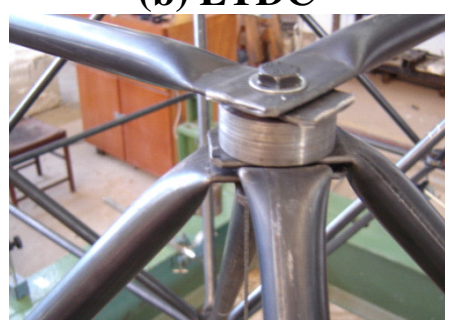

Figura 13. Nós estudados.

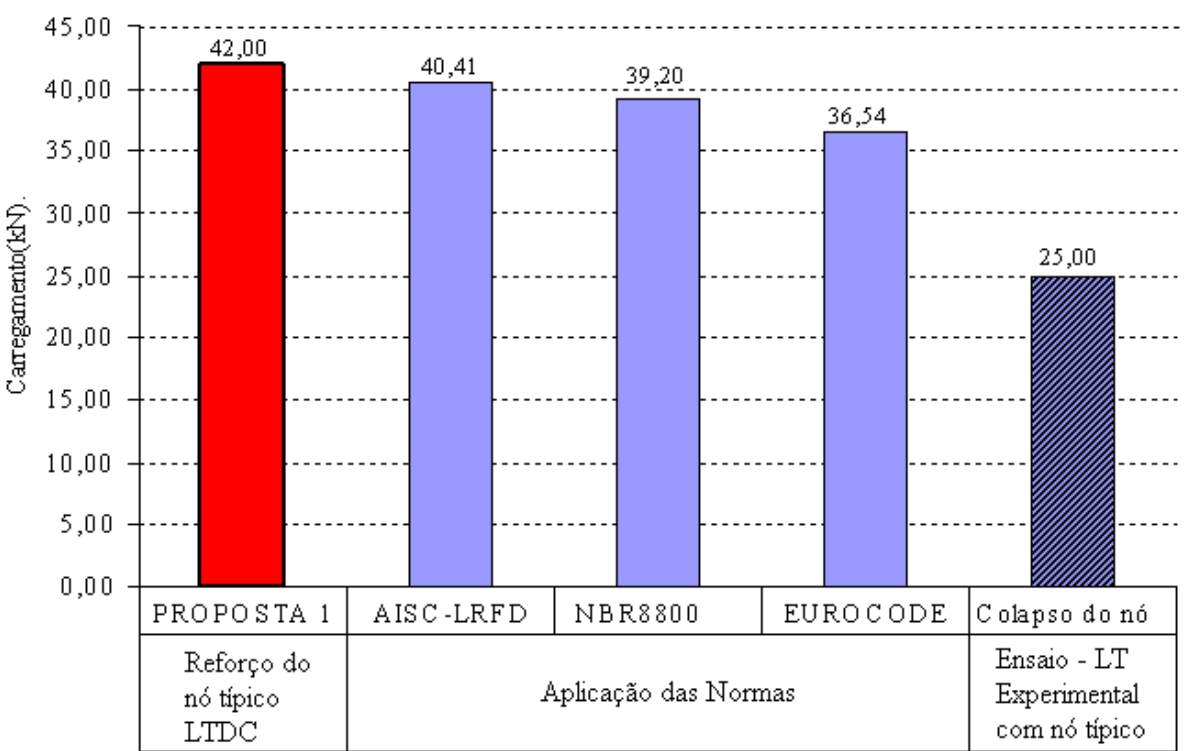

Figura 14. Comparação das cargas de colapso [4].

\section{ESTUDO EM MODELOS DE MAIORES VÃOS COM ELEMENTOS FINITOS DE BARRA}

Os estudos anteriores foram realizados em modelos reduzidos. Para avaliar a coerência e viabilidade da proposta foram realizados estudos numéricos, com elementos finitos de barra, em estruturas com vãos de 6mx9m (Fig.18), 9mx12m (Fig.19) e 12mx15m (Fig.20).

\subsection{Geometria e discretização dos modelos estudados}

Foram feitos 18 modelos, sendo suas respectivas características mostradas na Tabela 1. O modelo é um sistema modular com pirâmides com base de $1500 \mathrm{~mm}$ e altura "H" $\mathrm{mm}$. O ângulo de inclinação das diagonais é de $\alpha^{\text {o }}$. Os banzos e diagonais são compostos com tubos diâmetro $38 \mathrm{~mm}$ e parede de $2 \mathrm{~mm}$. Considerando as características geométricas dos protótipos 
e a Equação (1) foi calculado um distanciador para a ligação LTD. Para o estudo: Ligação ideal "LI", com barras centradas no nó, Figura 15; Ligação típica "LT", ver Figura 16; Ligação típica com distanciador "LTD”, Figura 17.

Tabela 1: Dimensões dos 18 modelos estudados.

\begin{tabular}{|c|c|c|c|c|}
\hline Altura $(\mathrm{H}) \mathrm{mm}$ & Ângulo $(\alpha)$ & Vão (m) & Tipos de Ligação & Distanciador (mm) \\
\hline \multirow{3}{*}{1061} & \multirow{3}{*}{45} & $6 \times 9$ & \multirow{3}{*}{ LI, LT, LTD } & \multirow{3}{*}{21,50} \\
\hline & & $9 \times 12$ & & \\
\hline & & $12 \times 15$ & & \\
\hline \multirow{3}{*}{750} & \multirow{3}{*}{32} & $6 \times 9$ & \multirow{3}{*}{ LI, LT, LTD } & \multirow{3}{*}{10,50} \\
\hline & & $9 \times 12$ & & \\
\hline & & $12 \times 15$ & & \\
\hline
\end{tabular}

Este estudo foi realizado numericamente aplicando o programa comercial SAP2000, que é fundamentado no método dos elementos finitos. Para a discretização das barras é utilizado o elemento "FRAME". Esse elemento é definido com dois nós, tendo seis graus de liberdade por nó (deslocamentos: UX, UY e UZ e rotações: RotX, RotY e RotZ) no modelo 3D ou dois graus de liberdade por nó (deslocamentos: UX e UY e rotações: RotX e RotY) no modelo 2D. Para a discretização do distanciador foi utilizado o elemento "SHELL". Esse elemento é definido com três ou quatro nós, tendo seis graus de liberdade por nó (deslocamentos: UX, UY e UZ e rotações: RotX, RotY e RotZ) no modelo 3D ou dois graus de liberdade por nó (deslocamentos: UX e UY e rotações: RotX e RotY) no modelo 2D. Restrições de terceiro gênero foram aplicadas nas extremidades das estruturas. Um carregamento vertical foi aplicado em 4 nós. As intensidades das cargas podem ser observadas na Tabela 2 e Figuras 21 a 23. Nesta também podem ser vistas os locais dos apoios, sendo adotado de $3^{\circ}$ gênero.

Tabela 2: Número de Elementos

\begin{tabular}{|c|c|c|c|c|c|}
\hline Tipo de Ligação & Vão (m) & $\mathrm{N}^{\mathrm{o}}$ de Barras & $\mathrm{N}^{\mathrm{o}}$ de Nós & $\mathrm{N}^{\mathrm{o}}$ de Placas & $\begin{array}{c}\text { Carga aplicada } \\
(\mathrm{kN})\end{array}$ \\
\hline LI & \multirow{3}{*}{$6 \times 9$} & 192 & 59 & - & \multirow{3}{*}{$\mathrm{P} 1=6,75$} \\
\hline LT & & 576 & 443 & - & \\
\hline LTD & & 960 & 1446 & 472 & \\
\hline LI & \multirow{3}{*}{$9 \times 12$} & 384 & 111 & - & \multirow{3}{*}{$\mathrm{P} 2=13,50$} \\
\hline LT & & 1152 & 879 & - & \\
\hline LTD & & 1920 & 2766 & 888 & \\
\hline LI & \multirow{3}{*}{$12 \times 15$} & 640 & 179 & - & \multirow{3}{*}{$\mathrm{P} 3=22,50$} \\
\hline LT & & 1920 & 1459 & - & \\
\hline LTD & & 3200 & 4502 & 1432 & \\
\hline
\end{tabular}

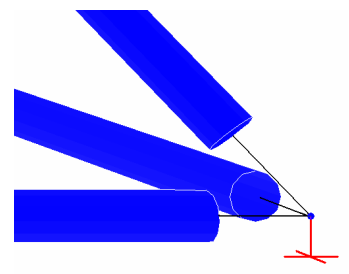

Figura 15. Ideal - LI.

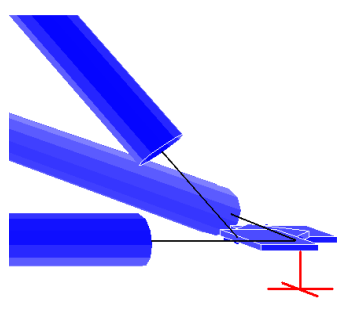

Figura 16. Típico - LT.

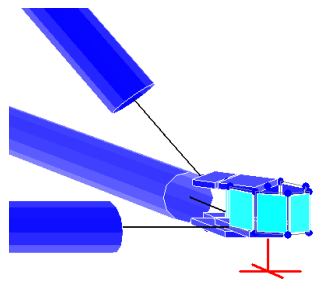

Figura 17. Distanciador - LTD. 


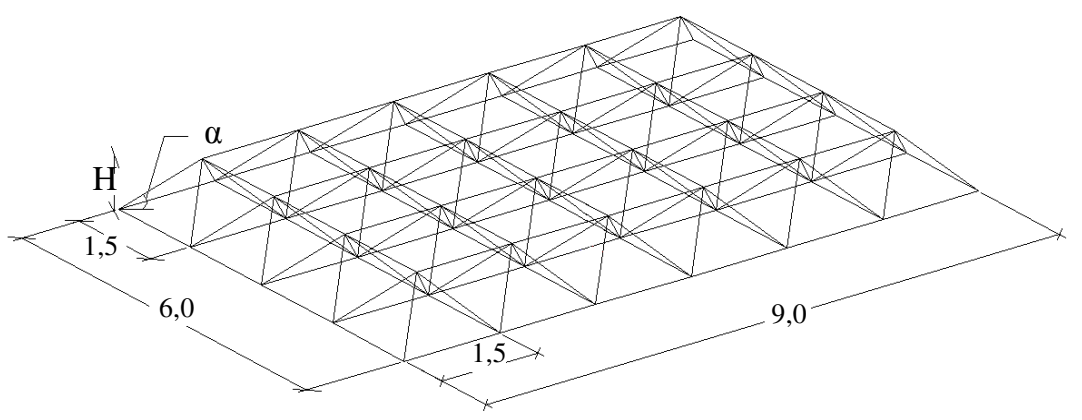

Figura 18. Modelo da estrutura treliçada 6x9m.

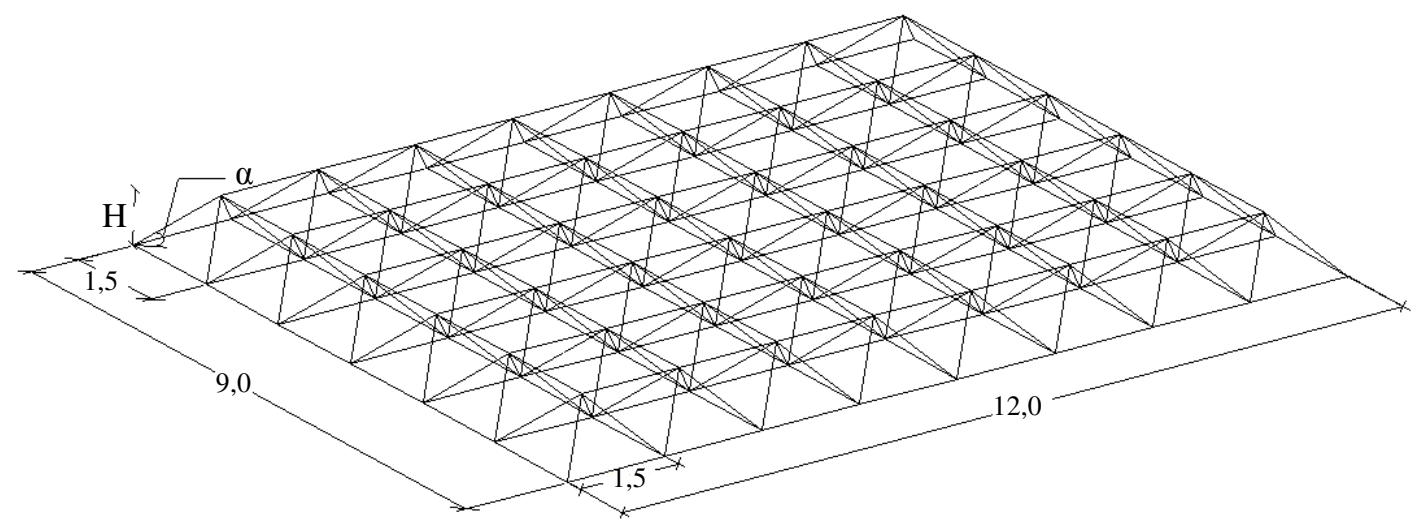

Figura 19. Modelo da estrutura treliçada 9x12m.

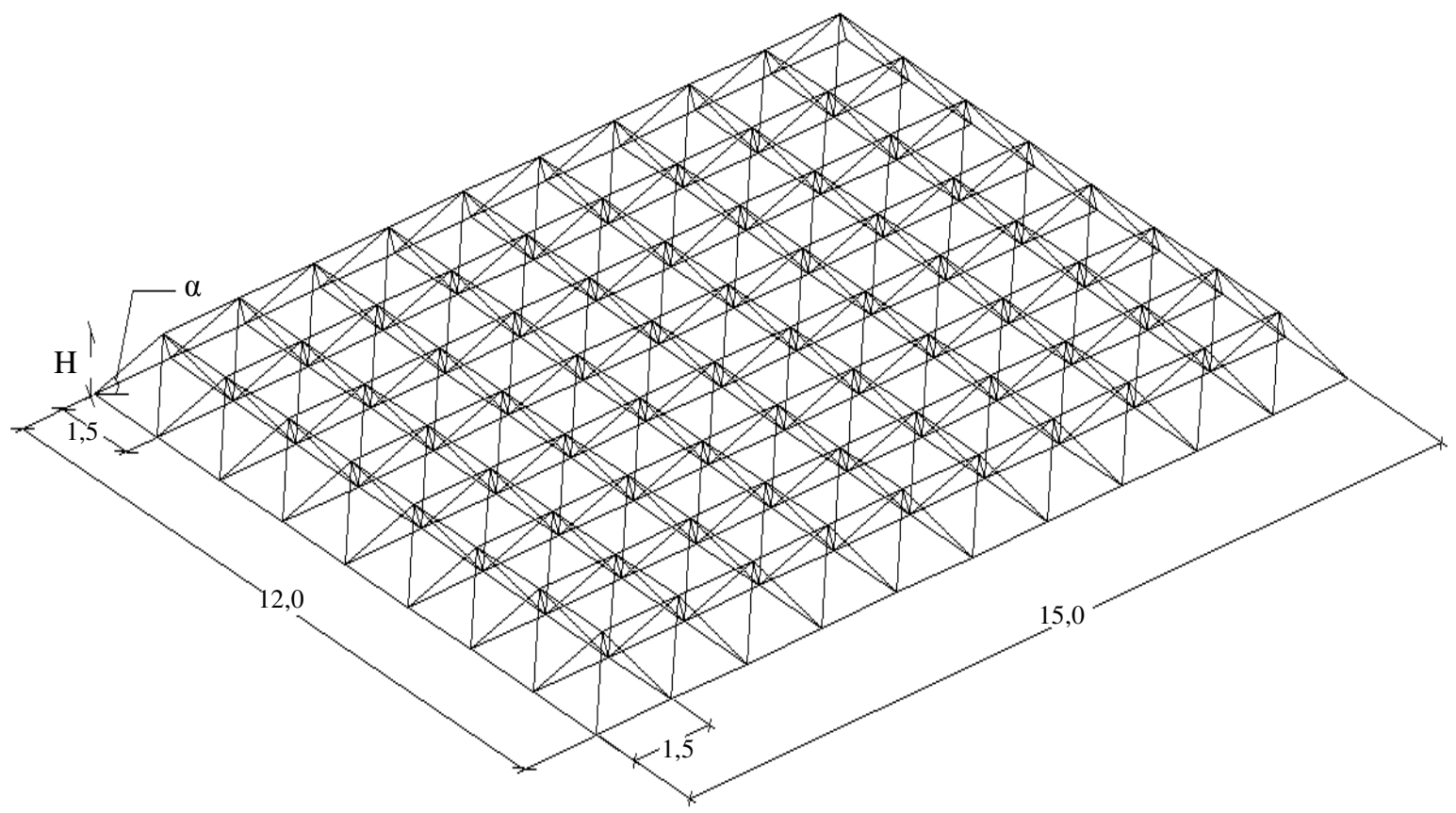

Figura 20. Modelo da estrutura treliçada 12x15m. 


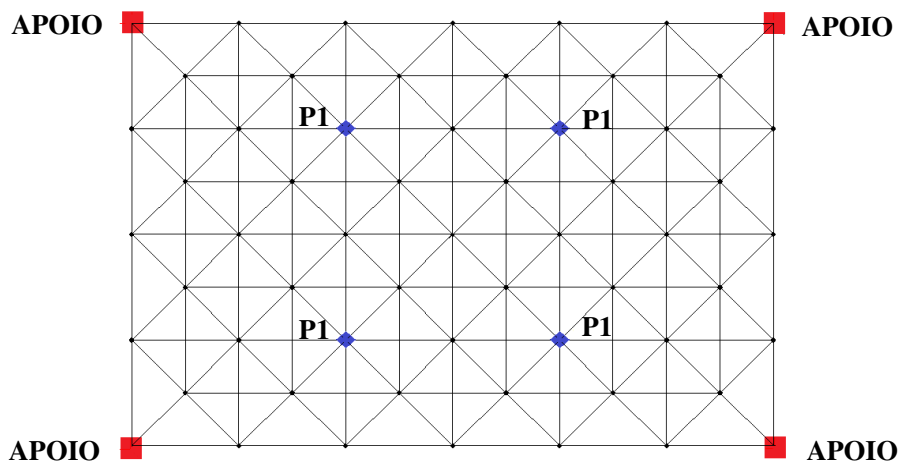

Figura 21. Restrições de apoio e Pontos de aplicação de carga do modelo de treliça 6x9m.

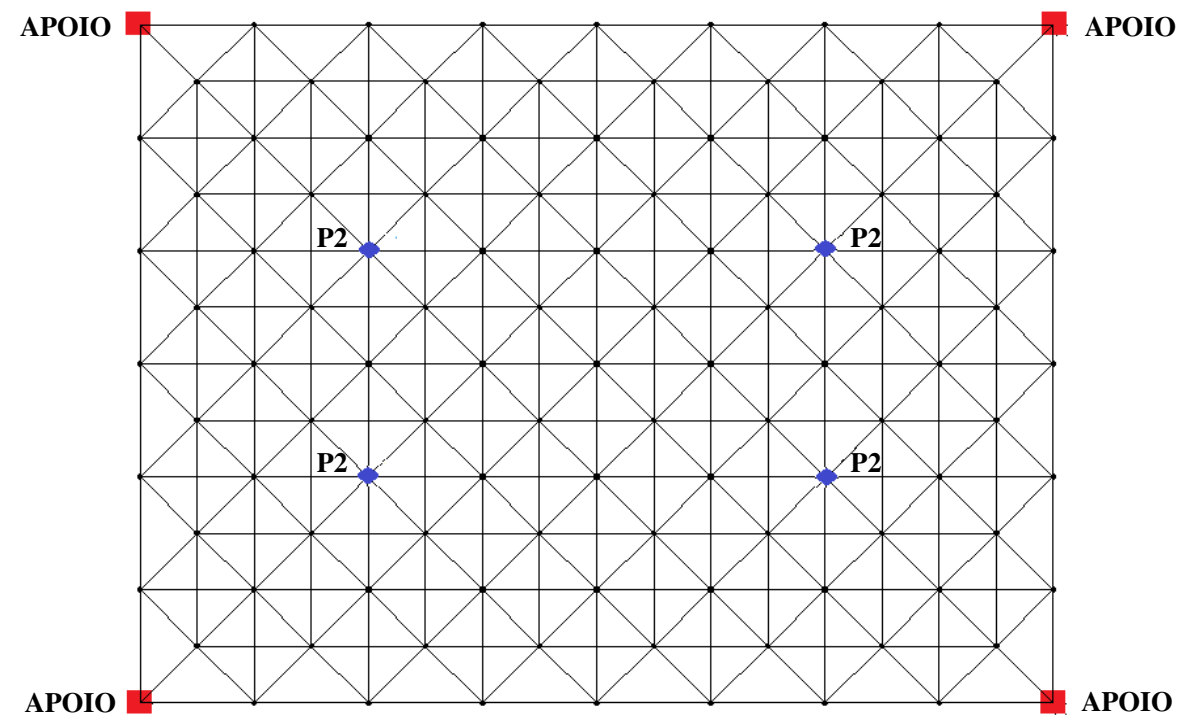

Figura 22. Restrições de apoio e Pontos de aplicação de carga do modelo de treliça 9x12m.

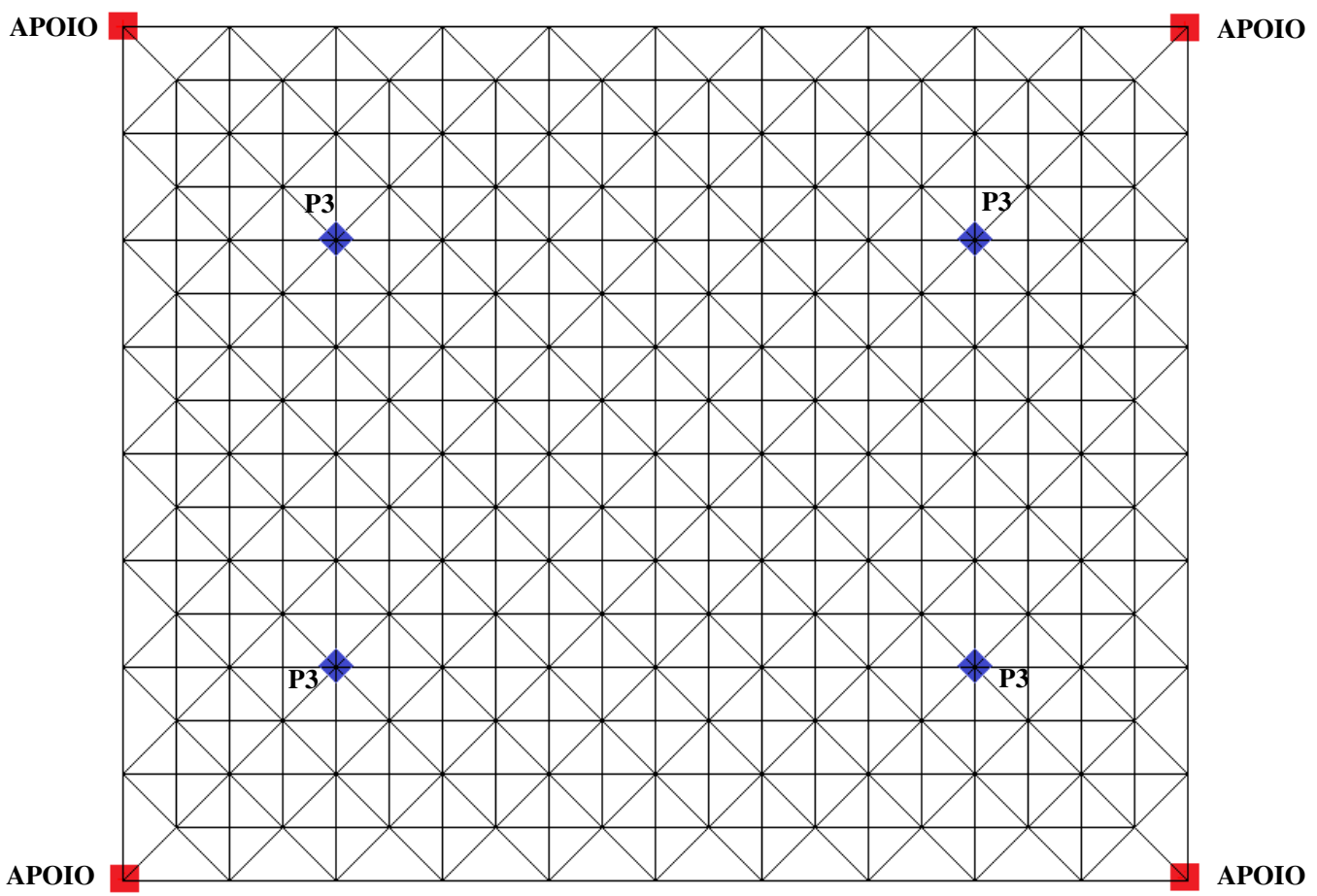

Figura 23. Restrições de apoio e Pontos de aplicação de carga do modelo de treliça 12x15m. 


\subsection{Esforços axiais nos elementos}

As Figuras 24 a 29 expõem os resultados dos esforços axiais $(\mathrm{kN})$ para os 18 modelos. Comparando os modelos com ligações LI, LT e LTD observa-se pouca variação na intensidade dos esforços.

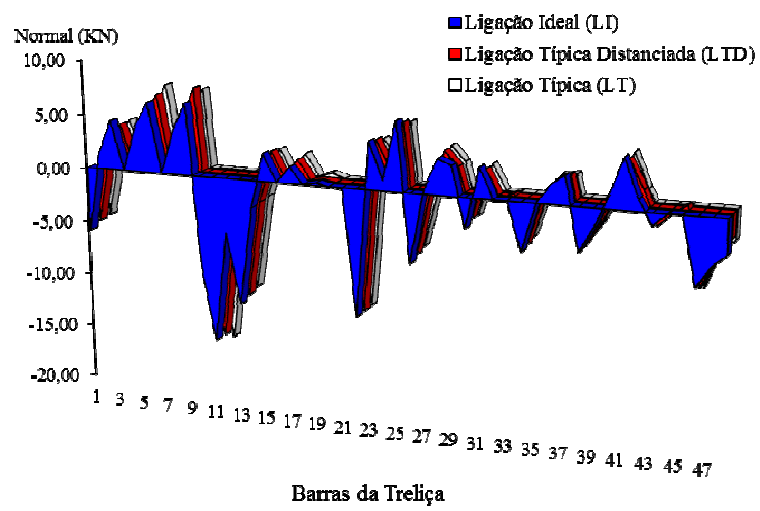

Figura 24. Esf. Axiais: 6x9m de $32^{\circ}$.

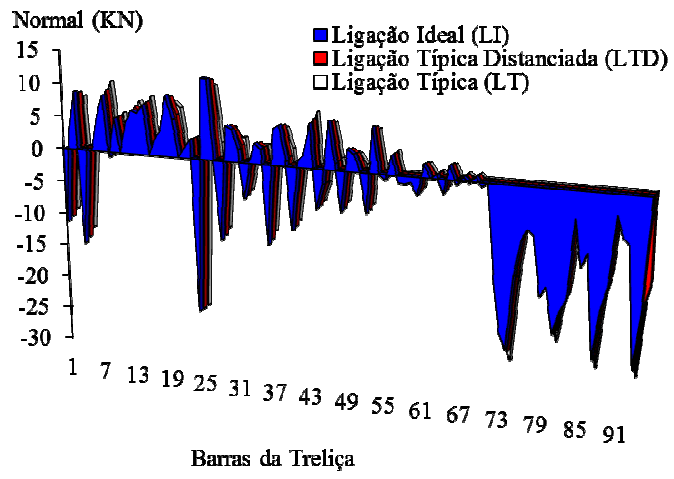

Figura 26. Esf. Axiais: 9x12m de $32^{\circ}$.

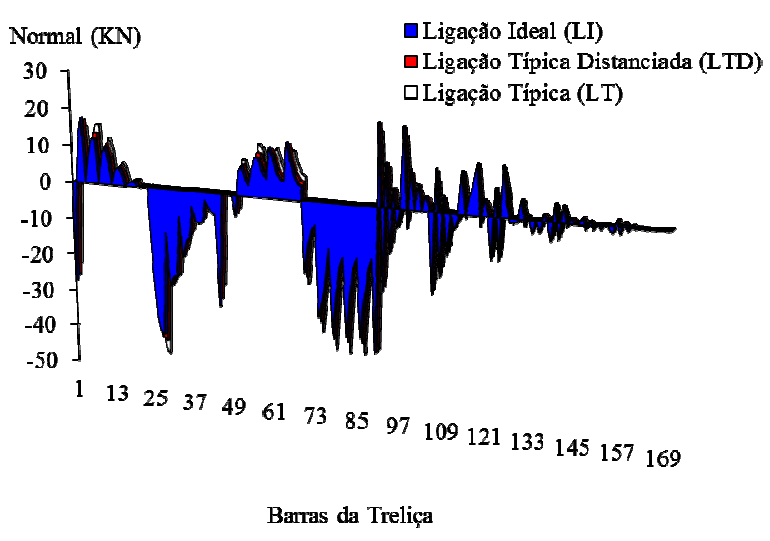

Figura 28. Esf. Axiais: $12 \times 15 \mathrm{~m}$ de $32^{\circ}$.

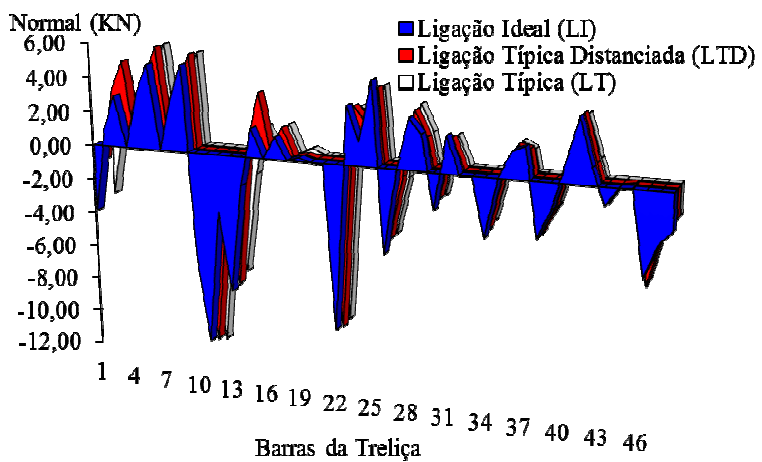

Figura 25. Esf. Axiais: $6 \times 9 \mathrm{~m}$ de $45^{\circ}$.

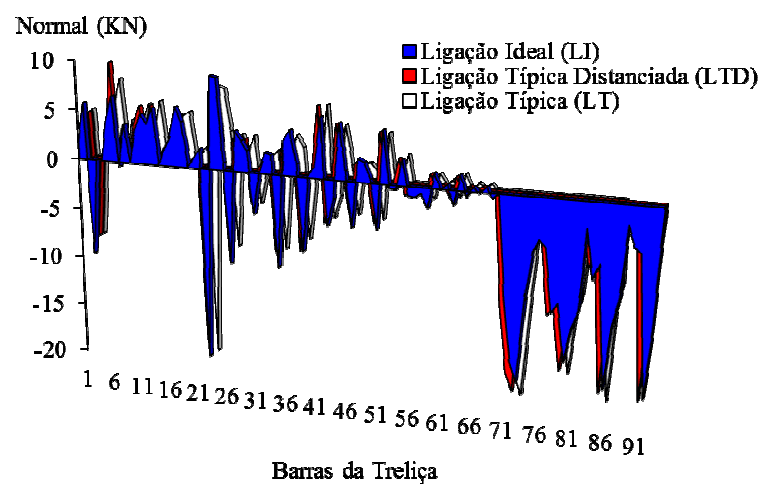

Figura 27. Esf. Axiais: 9x12m de $45^{\circ}$.

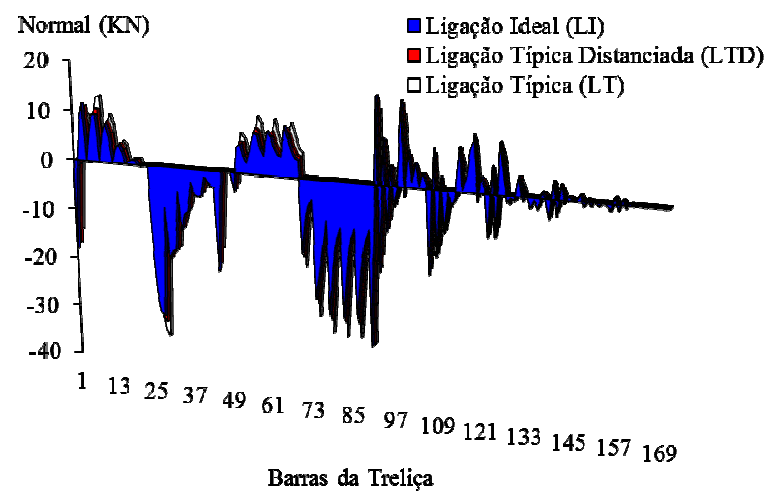

Figura 29. Esf. Axiais: $12 \times 15 \mathrm{~m}$ de $45^{\circ}$. 


\subsection{Momentos fletores nas estruturas}

As Figuras 30 a 35 expõem os resultados dos Momentos Fletores (kN.cm) para os 18 modelos. Comparando os modelos com ligações LI, LT e LTD observa-se uma redução do momento nos modelos com ligações LTD em relação às ligações LT.

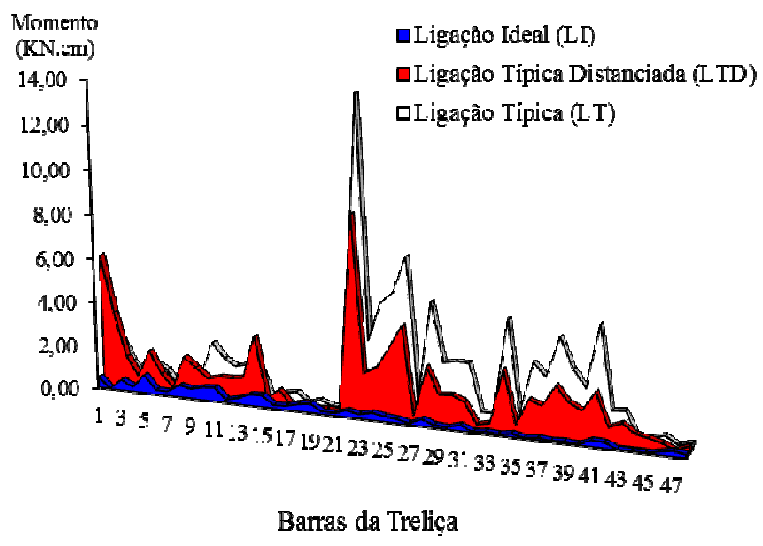

Figura 30. Mom. fletores: 6x9m de $32^{\circ}$.

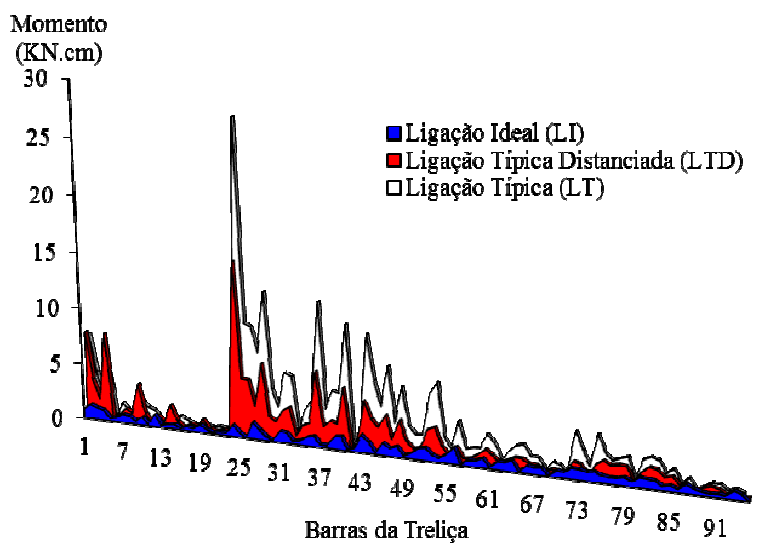

Figura 32. Mom. fletores: 9x12m de $32^{\circ}$.

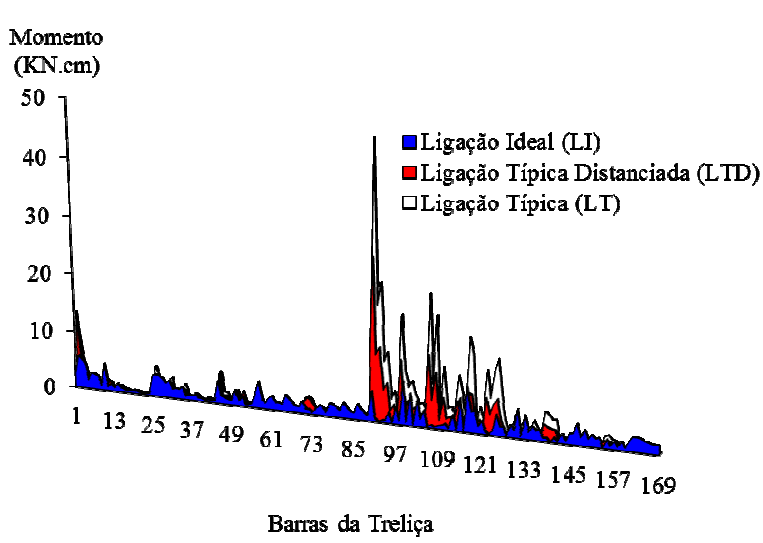

Figura 34. Mom. fletores: $12 \times 15 \mathrm{~m}$ de $32^{\circ}$.

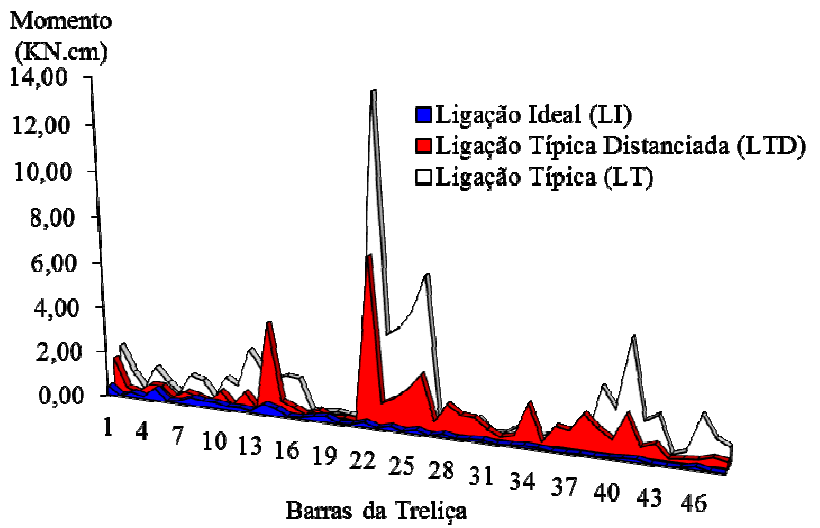

Figura 31. Mom. fletores: 6x9m de $45^{\circ}$.

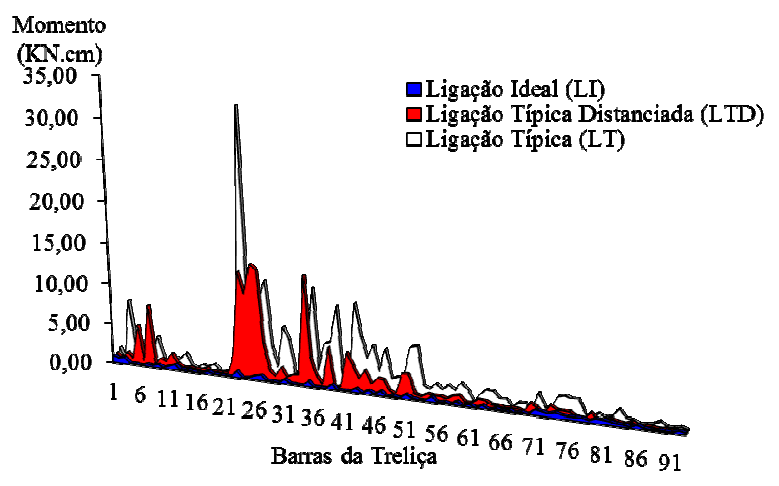

Figura 33. Mom. fletores: 9x12m de $45^{\circ}$.

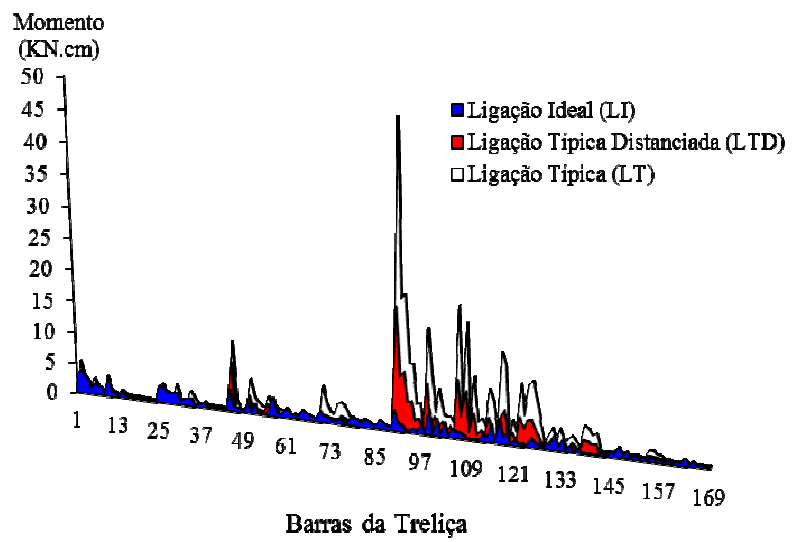

Figura 35. Mom. fletores: $12 \times 15 \mathrm{~m}$ de $45^{\circ}$.

É notório que os momentos na estrutura com ligação ideal (LI) são desprezíveis, confirmando o que é adotado na literatura, quando as linhas de centro das barras se unem no centro do nó. Entretanto, a ligação típica (LT) apresenta elevados valores de momento fletor 
nos nós, provavelmente devido à excentricidade intrínseca deste sistema. Quanto ao modelo proposto neste trabalho, ligação com correção da excentricidade com distanciador (LTD), nota-se uma redução no momento fletor. Esta redução no momento fletor diminui a solicitação nodal e pode aumentar a resistência última da estrutura.

\subsection{Deslocamentos verticais nos nós das estruturas}

No gráfico das Figuras 36 a 41, estão dispostos os resultados dos deslocamentos verticais. Os modelos foram analisados com $1 / 4$ do seu tamanho real, por simetria os esforços solicitantes serão os mesmos em toda a estrutura.

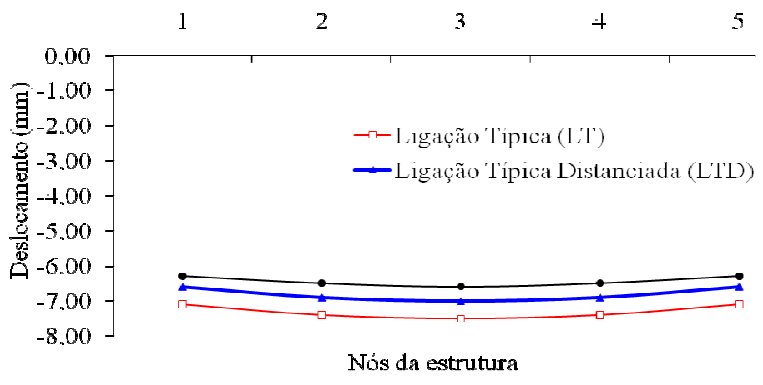

Figura 36. Deslocamento vertical: $6 \times 9 \mathrm{~m} / 32^{\circ}$.

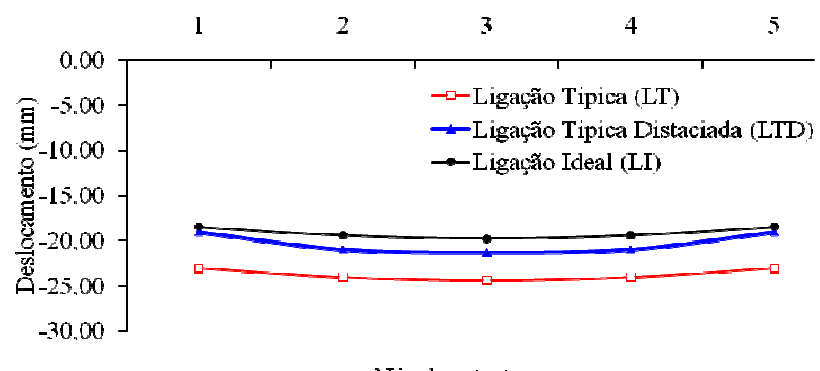

Figura 38. Deslocamento vertical: 9x12m/32 .

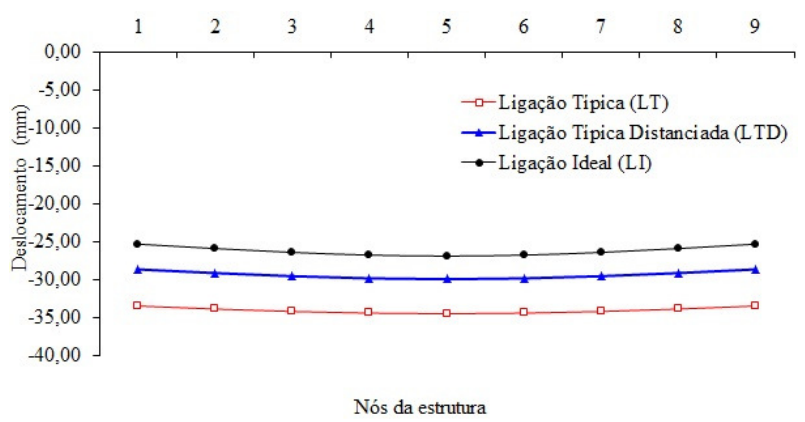

Figura 40. Deslocamento vertical: $12 \times 15 \mathrm{~m} / 32^{\circ}$

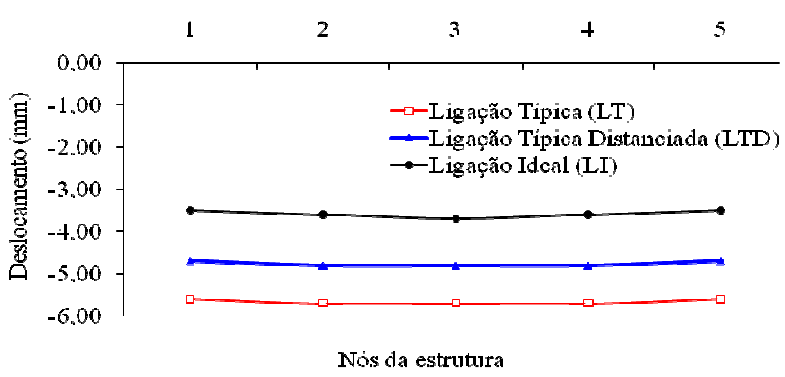

Figura 37. Deslocamento vertical:6x9m/ 45 .

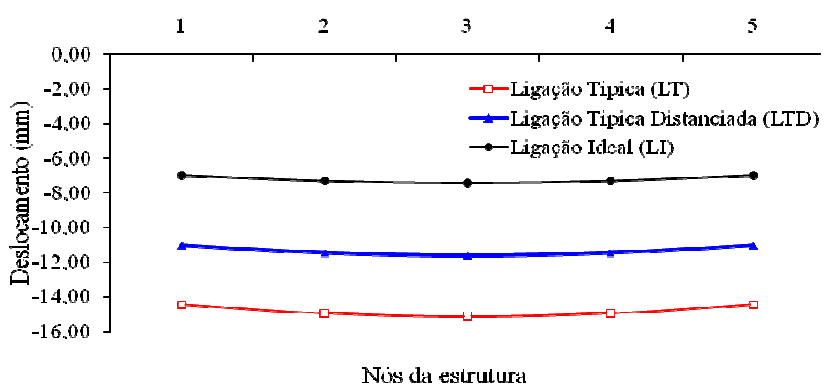

Figura 39. Deslocamento vertical: $9 \times 12 \mathrm{~m} / 45^{\circ}$.

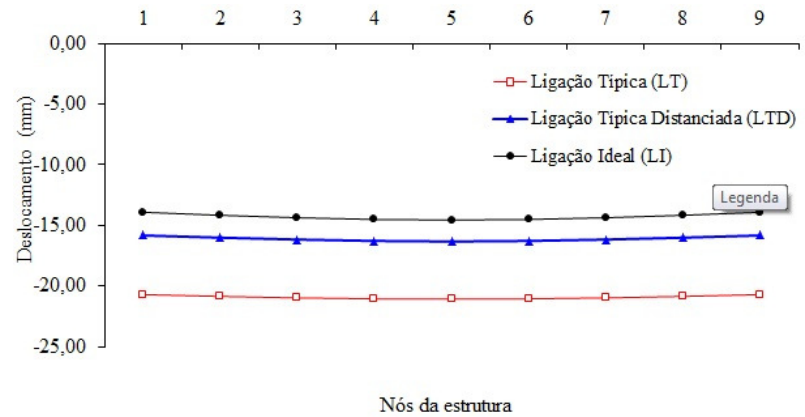

Figura 41. Deslocamento vertical: $12 \times 15 \mathrm{~m} / 45^{\circ}$

\subsection{Conclusão preliminar}

Após o estudo comparativo observou-se que as estruturas com nó típico (LT) apresentam maiores momentos fletores e deslocamentos verticais em relação ao nó ideal (LI) e ao nó típico com distanciador (LTD). A ligação proposta (LTD) apresentou uma melhoria estrutural 
às estruturas em relação ao nó típico (LT). Estruturas com ângulos de inclinação das diagonais de $45^{\circ}$ apresentaram maior rigidez estrutural. É importante salientar que tal estudo respalda a necessidade de estudos experimentais para maiores conclusões quanto à aplicação da ligação proposta (LTD).

Por razões econômicas e de infraestrutura, foi escolhido os protótipos com dimensões $6 \mathrm{mx} 9 \mathrm{~m}$, para futuros ensaios experimentais. Desta forma, foi realizada uma investigação computacional, com elementos finitos de placa deste modelo. Esta etapa é necessária para prever condições de ensaio e futuras comparações de resultados numéricos x experimental.

\section{ESTUDO NUMÉRICO COM ELEMENTOS FINITOS DE PLACA DO MODELO A SER ENSAIADO EXPERIMENTALMENTE}

Por motivos já expostos para esta etapa do estudo, foi adotado um modelo de treliça tridimensional de acordo com a Figura 18. Tal geometria será discretizada com elementos de placa (SHELL). Foram feitas dois modelos, sendo um modelo com a ligação típica "LT" e outro com a ligação típica com distanciador "LTDC".

\subsection{Discretização do modelo com elementos de placa}

O programa de análise, fundamentado no método de elementos finitos, aplicado no estudo foi o SAP2000_V10. Os elementos das treliças foram discretizados com elementos de placa SHELL, ver Figura 42. O elemento "SHELL" é um elemento de placa usado para uma modelagem bidimensional ou tridimensional. Esse elemento é definido com três ou quatro nós, tendo seis graus de liberdade por nó (deslocamentos: UX, UY e UZ e rotações: RotX, RotY e RotZ) no modelo 3D.

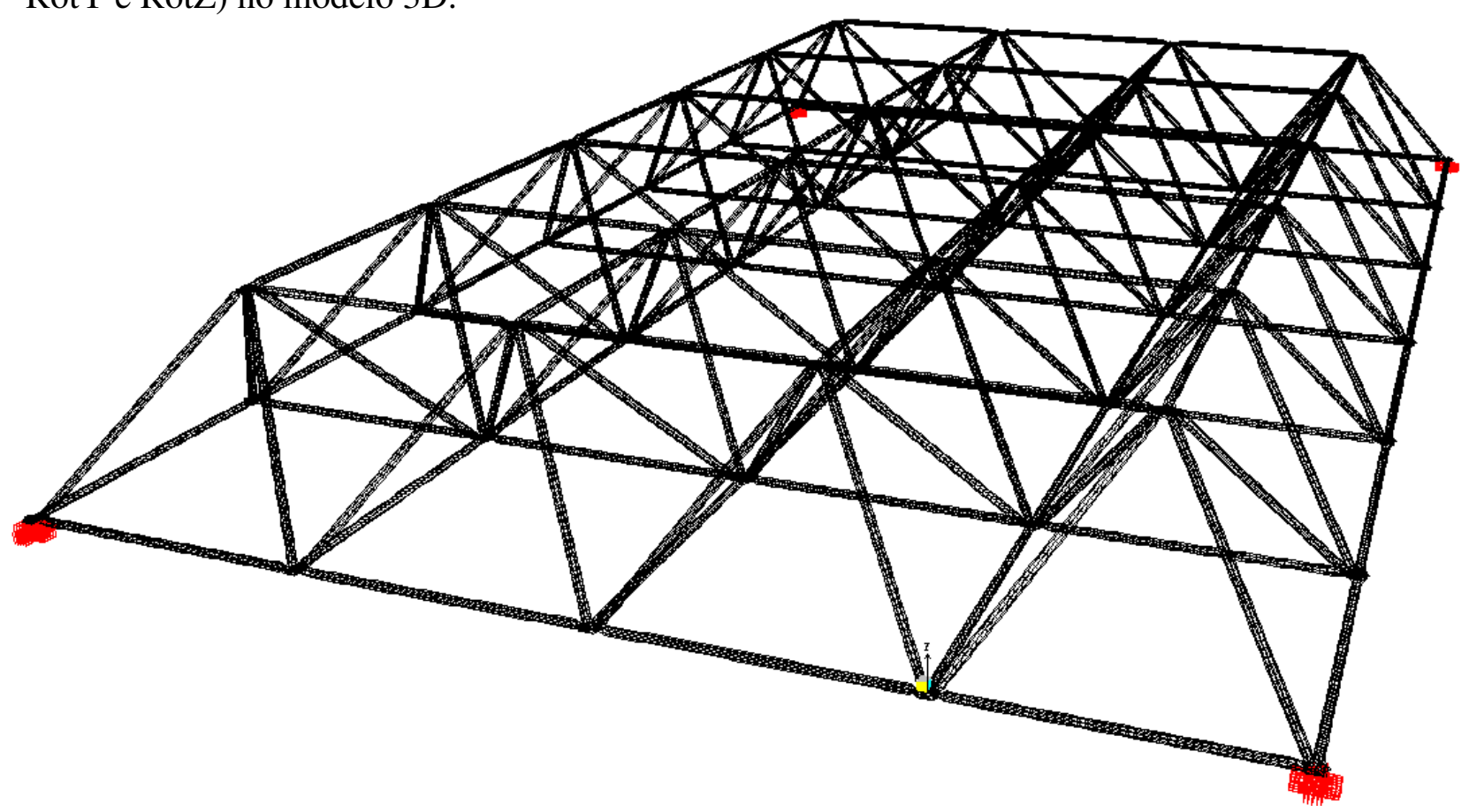

Figura 42. Discretização do modelo $6 \mathrm{~m}$ x 9m em elementos finitos. 
O carregamento foi aplicado nos pontos como indicados na Figura 43. Este foi aplicado na estrutura distribuindo a carga em quatro pontos de aplicação. A carga pontual foi de intensidade $6,75 \mathrm{kN}$ (Figura 44), totalizando $27 \mathrm{kN}$ (nos quatro pontos). A Figura 45 mostra em detalhe os nós de apoio, onde foram aplicadas as restrições de $3^{\circ}$ gênero.

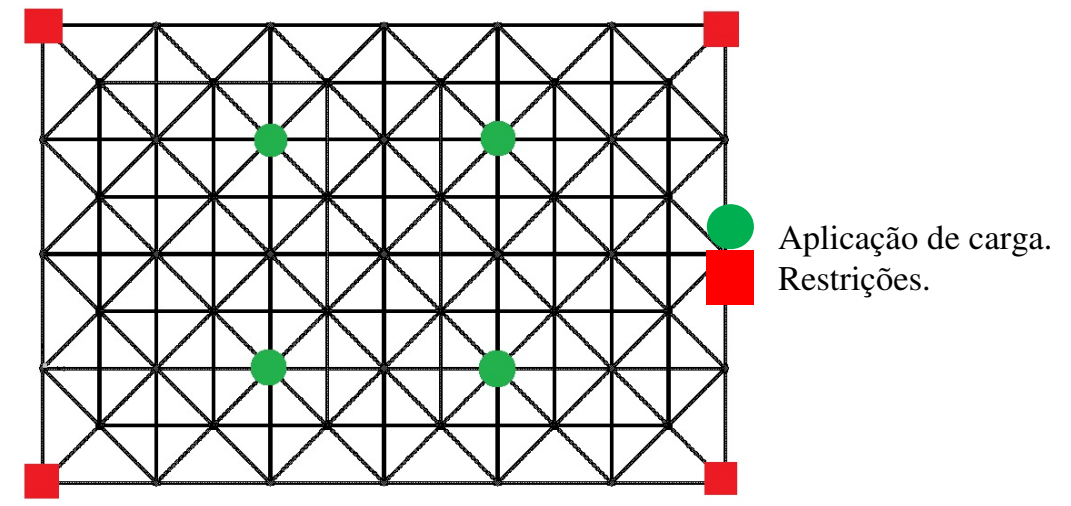

Figura 43. Detalhe das restrições no apoio

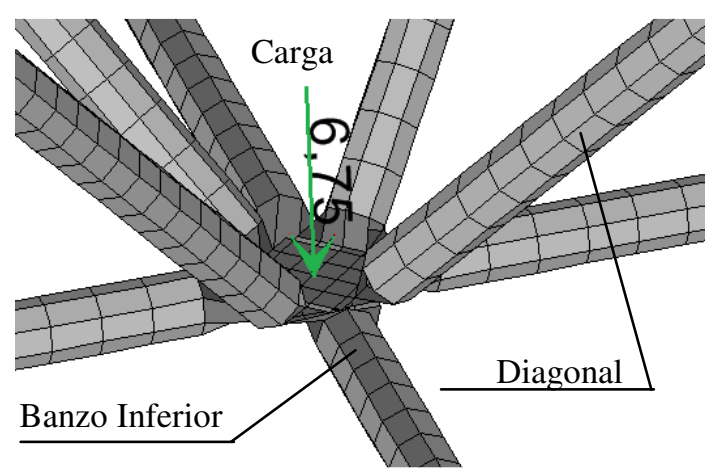

Figura 44. Detalhe do ponto de carga.

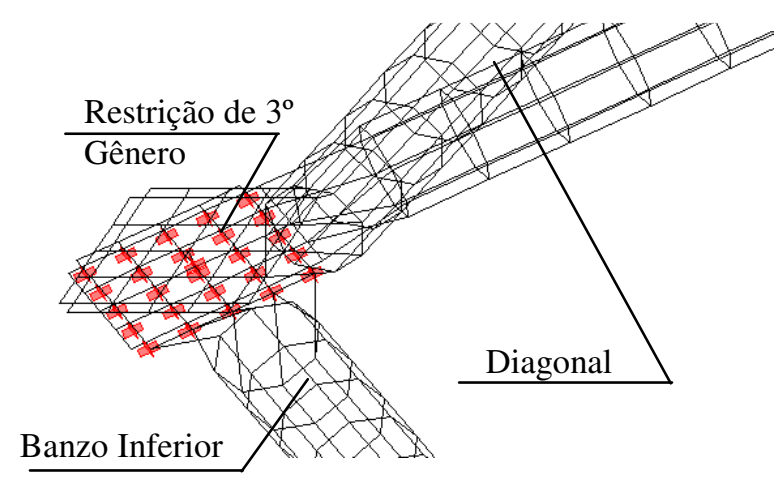

Figura 45. Detalhe das restrições no apoio

\subsection{Discretização da estrutura com nó típico (LT)}

Na discretização da estrutura treliçada com nó típico foram utilizados 72372 elementos de placa (SHELL), com espessura de 1,2mm, e um total de 72348 nós. Entre estes elementos tem-se 66045 para os tubos (banzos e diagonais) e 3776 elementos para as extremidades amassadas. A Figura 46 da ênfase ao detalhe da ligação típica. Na ligação entre banzos e diagonais foi aplicado parafusos discretizados em 59 elementos de barras (FRAME). O comprimento do parafuso foi considerado de acordo cm a demonstração das Figuras 47 e 48.

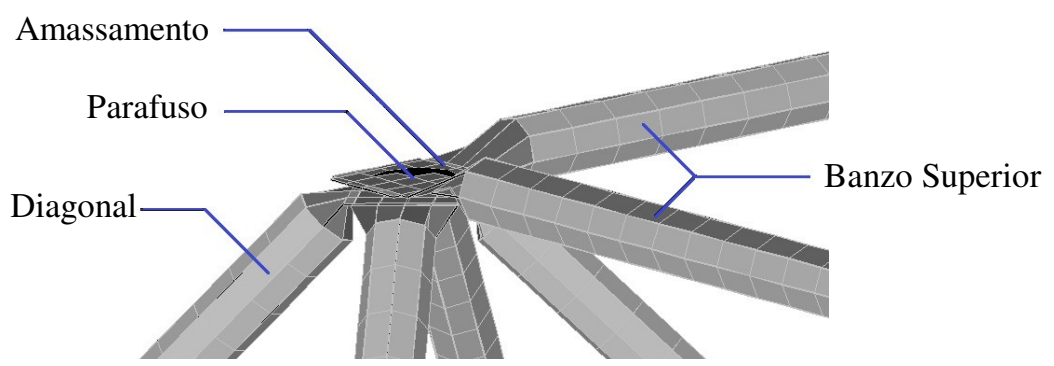

Figura 46. Detalhe da ligação com nó típico (LT). 


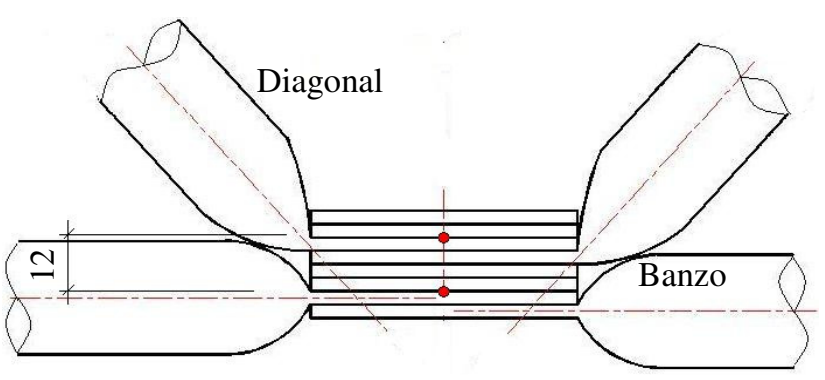

Figura 47. Comprimento do parafuso - LT.

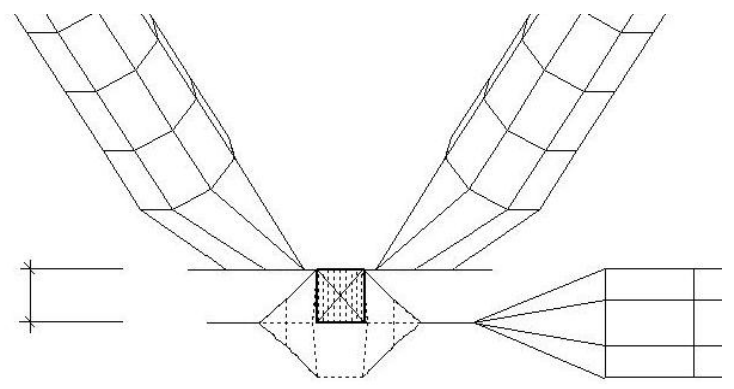

Figura 48. Discretização - LT.

\subsection{Discretização da estrutura com nó típico, distanciador e cobrejunta (LTDC)}

Considerando as características geométricas dos protótipos e considerando a Equação (1) foi adotado um distanciador com altura de $28,0 \mathrm{~mm}$. As chapas cobrejunta são quadradas com largura de 50,0mm e espessura de CH\#3/4".

$\mathrm{Na}$ discretização da estrutura treliçada tridimensional com típico e distanciador (LTDC) foram utilizados 71854 elementos de placa (SHELL), com um total de 73012 nós. Entre estes elementos tem-se 65524 elementos de placa com espessura de 1,2mm para os tubos (banzo e diagonais), 6330 elementos de placa com espessura de $8 \mathrm{~mm}$ ( $3 \mathrm{~mm}$ para o tubo $+5 \mathrm{~mm}$ para a chapa cobrejunta) para as extremidades amassadas. Utilizados ainda, 59 elementos frame com $28 \mathrm{~mm}$ de altura para os distanciadores e 59 elementos de barras (FRAME) com $5 \mathrm{~mm}$ de diâmetro para composição dos parafusos.

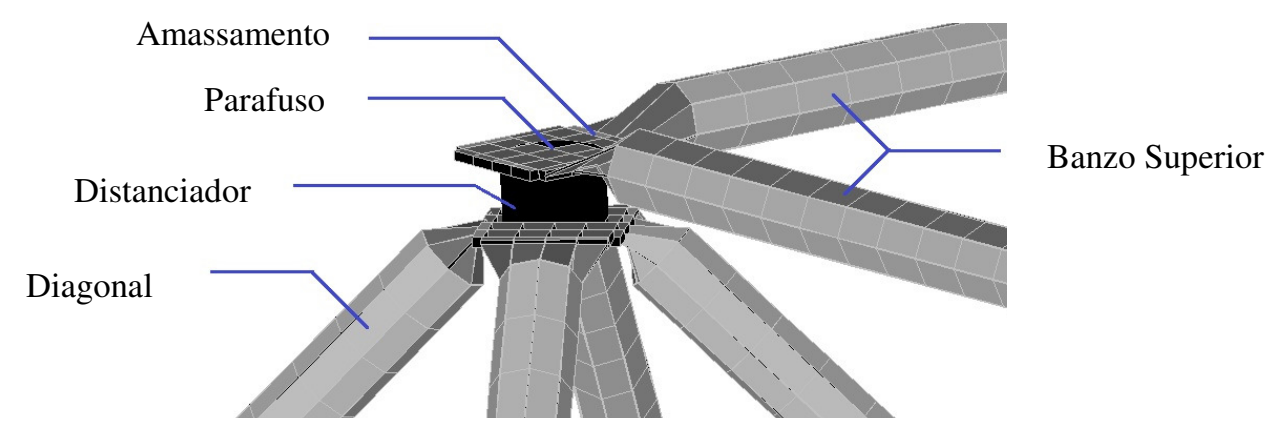

Figura 49. Detalhe da ligação com nó típico, distanciador e cobrejunta (LTDC).

\subsection{Resultados do estudo numérico}

As Figuras 50 e 51 mostram, respectivamente, os deslocamentos dos modelos com nó típico (LT) e nó típico com distanciador (LTD). É possível observar que houve uma redução do deslocamento vertical da estrutura com distanciador $(Z=12,16 \mathrm{~mm})$ de $68 \%$ em relação à estrutura com nó típico $(Z=38,32 \mathrm{~mm})$. 


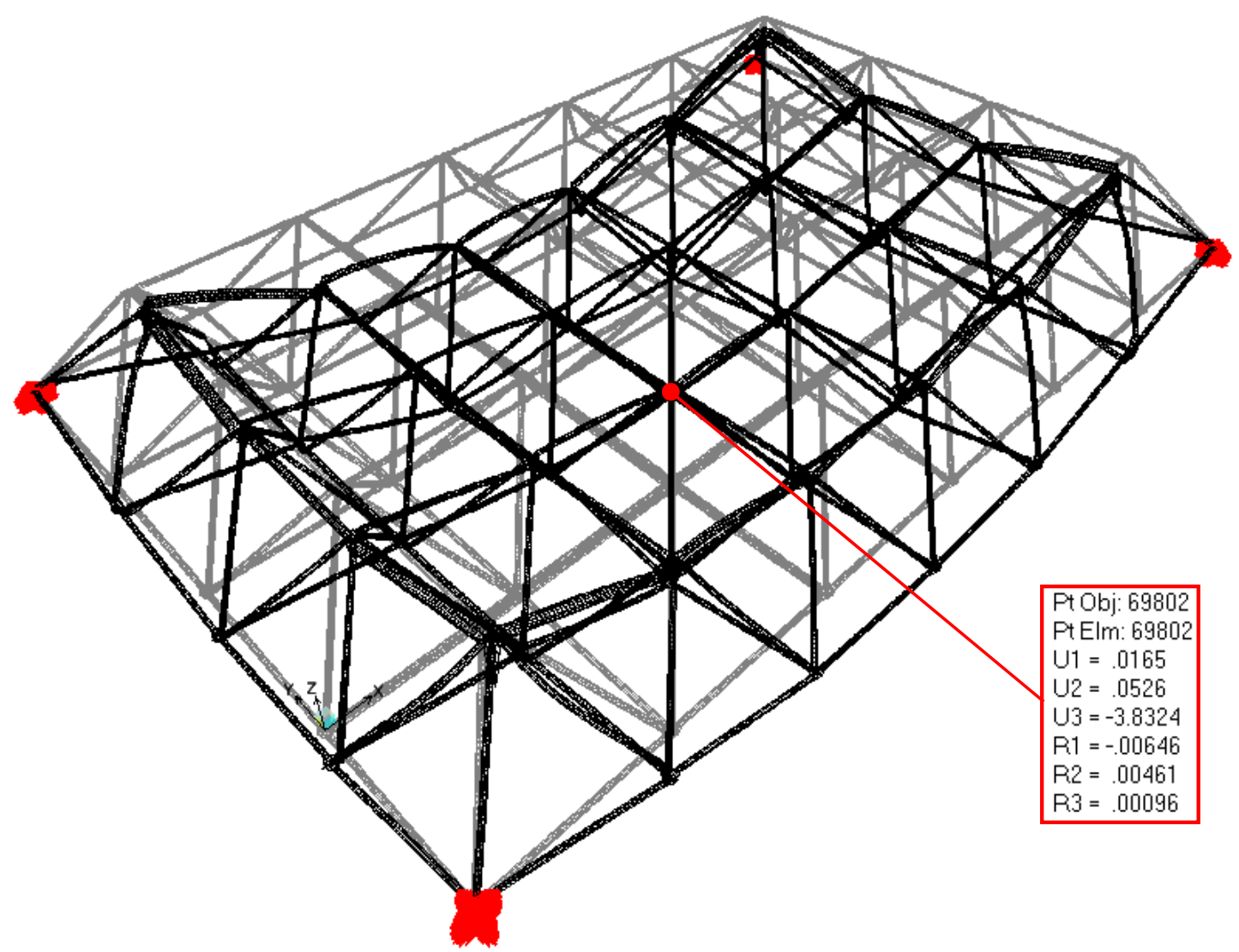

Figura 50. Deslocamentos da estrutura com nó típico - LT (cm).

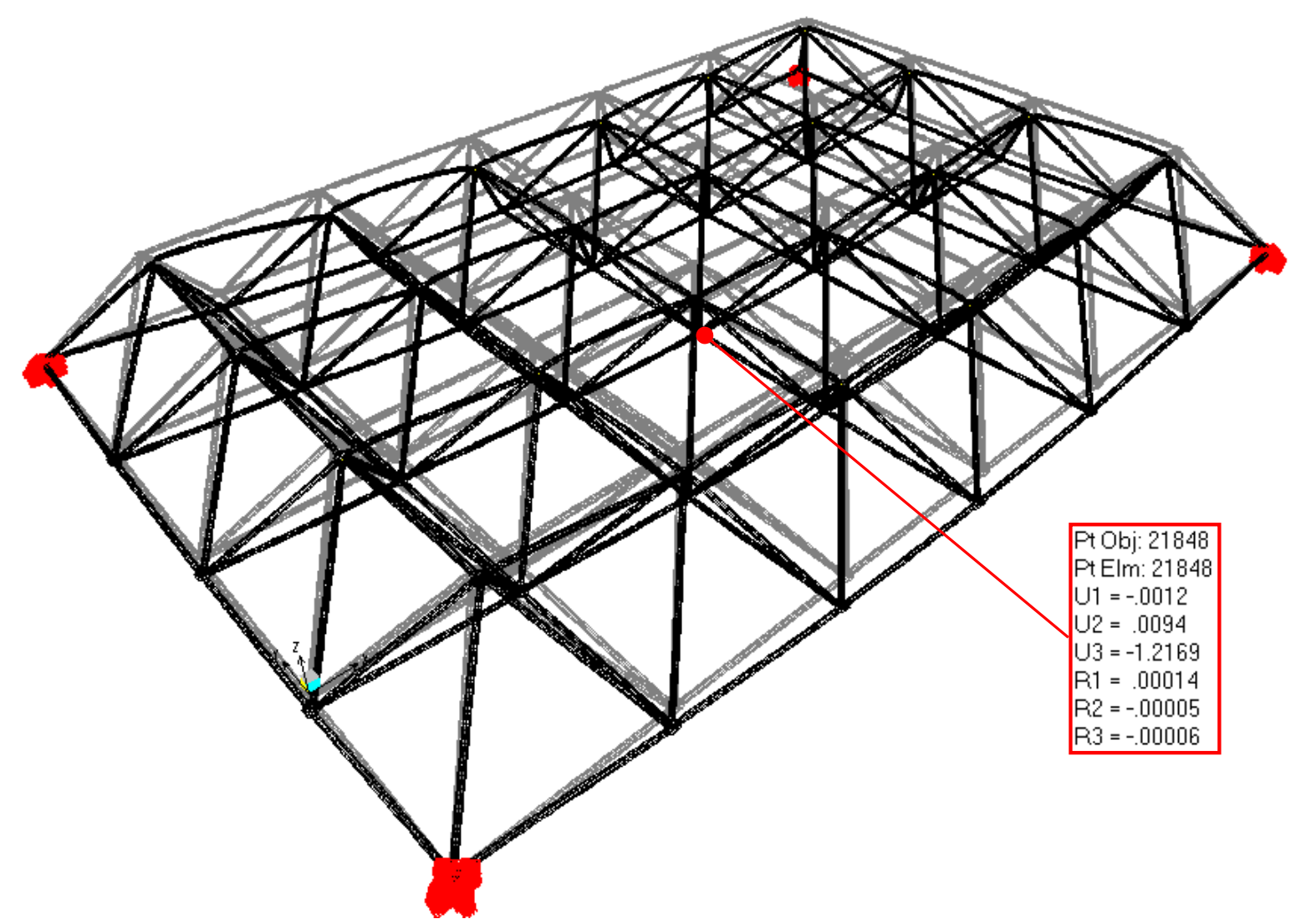

Figura 51. Deslocamentos da estrutura com nó típico e distanciador - LTD (cm). 
As Figuras 52 e 53 mostram os diagramas de distribuição das tensões, respectivamente para os modelos LT e LTD. É possível notar que as ligações típicas (LT), apresentam grande concentração de tensão, e que estas são consideravelmente aliviadas com a utilização do distanciador (LTD).

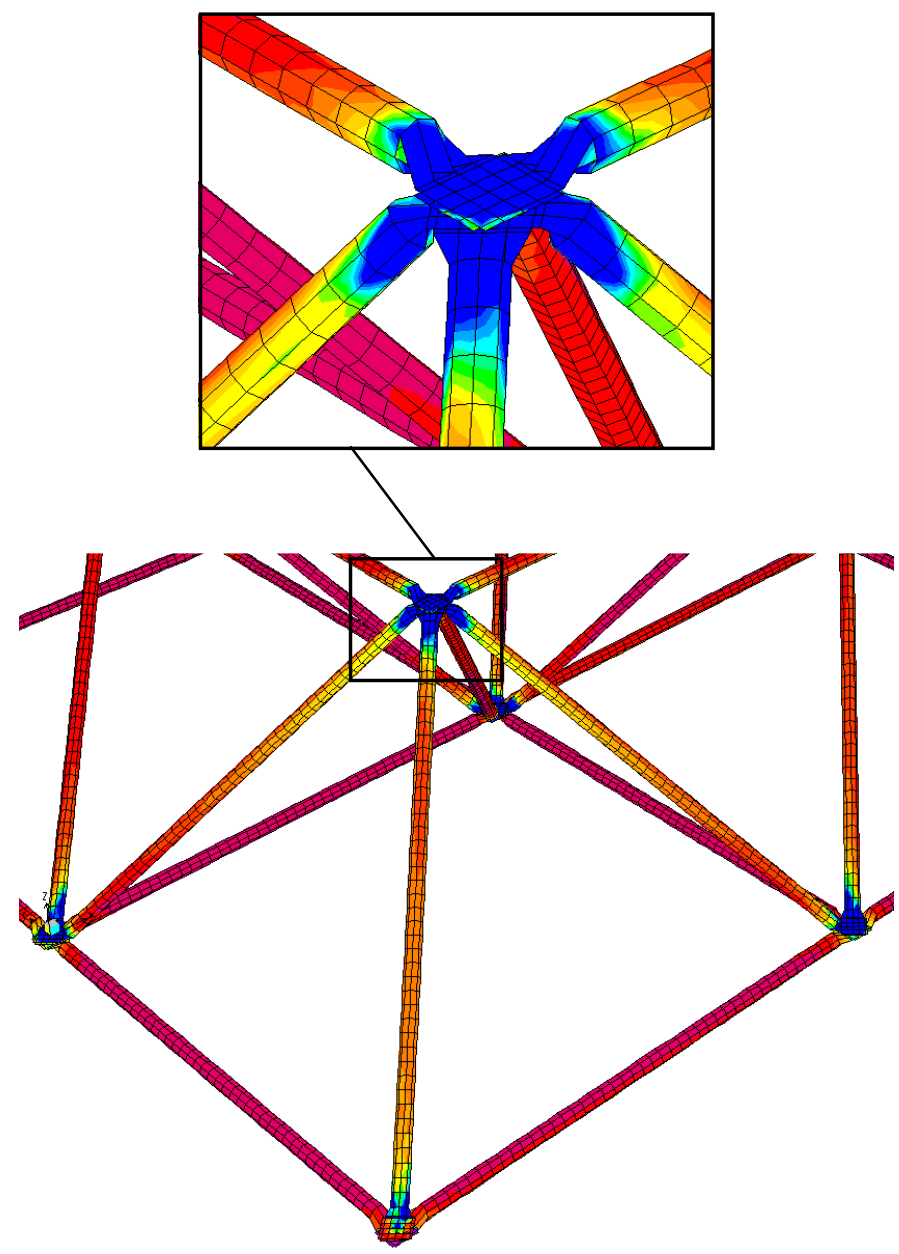

Figura 52. Tensões de Von Misses - LT $\left(\mathrm{kN} / \mathrm{cm}^{2}\right)$.

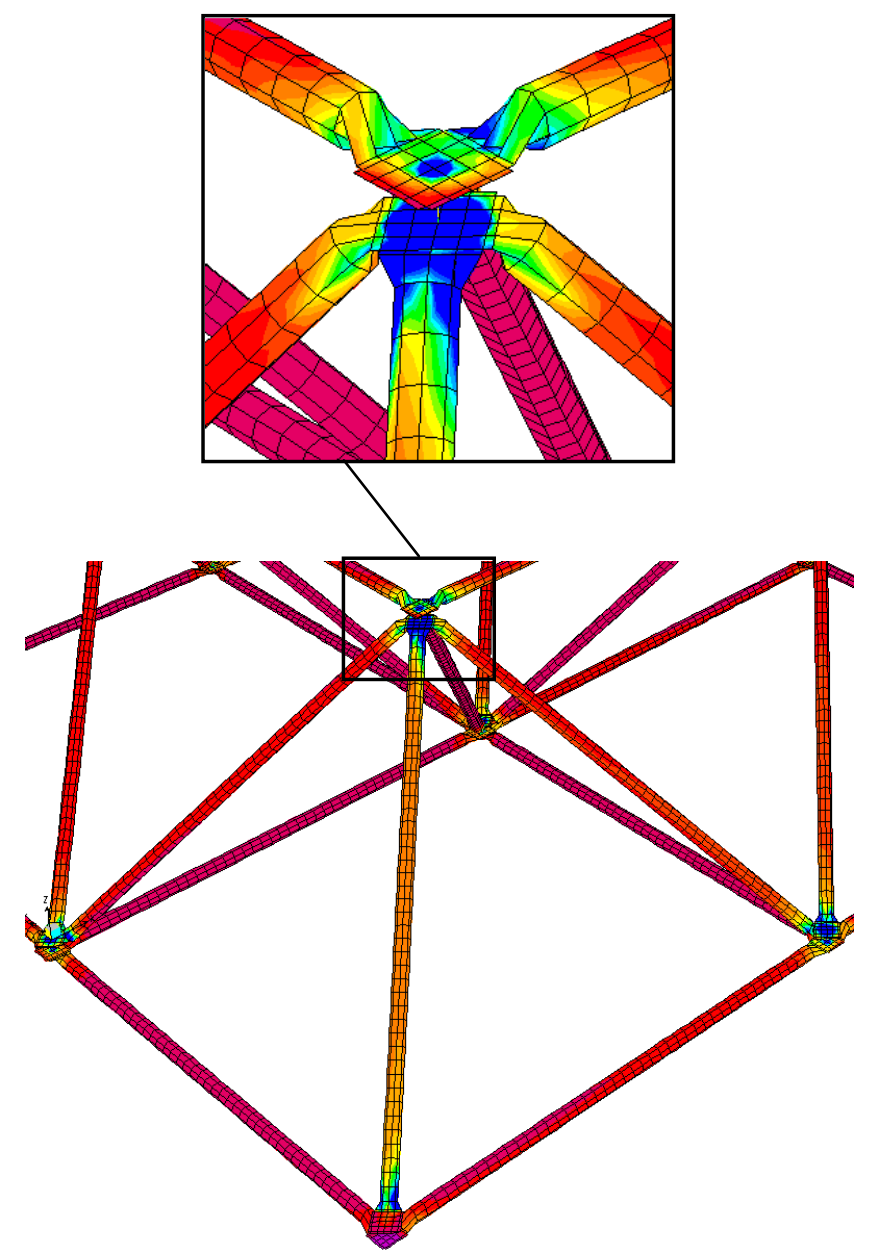

Figura 53. Tensões de Von Misses - LTD $\left(\mathrm{kN} / \mathrm{cm}^{2}\right)$.

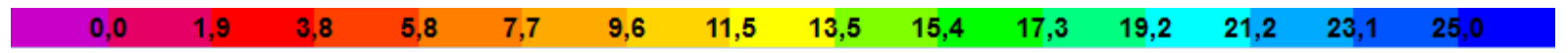

\section{CONCLUSÃO}

Após a análise de diferentes modelos, discretizados com elementos finitos de barra, observou-se a redução do momento fletor e do deslocamento vertical em modelos com ligação típica e distanciador (LTD) em relação à ligação típica (LT).

O estudo do modelo discretizado com elementos finitos de placa mostrou uma redução no deslocamento vertical e alívio das tensões na ligação proposta (LTD) em relação à LT. Respaldando desta forma a necessidade de ensaios experimentais. Protótipos com vãos $6 \mathrm{mx} 9 \mathrm{~m}$ estão sendo montados e instrumentados no laboratório de estruturas na UFC Campus Cariri. 


\section{Agradecimentos}

Os autores agradecem ao valoroso apoio financeiro da Fundação Cearense de Apoio ao Desenvolvimento Científico e Tecnológico (FUNCAP), ao CNPq e a UFC-Campus Cariri.

\section{REFERÊNCIAS}

[1] American Institute of Steel Construction. AISC - LRFD - "Manual of steel construction". Chicago, 1999.

[2] Associação Brasileira de Normas Técnicas, NBR 8800 - "Projeto e execução de estruturas de aço de edifícios: método dos estados limites". Rio de Janeiro, 1986.

[3] European Commitee For Standardization. Eurocode 3. Design of steel structures. Part.1.1. General rules and rules for buildings 1992.

[4] Freitas, C. A. S., Estudos experimental, numérico e analítico de conexões de estruturas espaciais em aço com correção e reforço na ligação típica estampada. Tese de doutorado, Departamento de Engenharia Civil e Ambiental, Universidade de Brasília, Brasília, 2008.

[5] Freitas, C.A.S.; Bezerra, L.M.; Nagato, Y., Increasing load capacity of steel space trusses with staking end-flattened connections. Journal of constructional steel research - Elservier, 2008.

[6] Souza, A. S. C., Analise teórica e experimental de treliças espaciais - Tese de Doutorado, Escola de Engenharia de São Carlos, EESC/USP, São Paulo, 2003. 